\title{
A Systematic Literature Review of Animal-Assisted Interventions in Oncology (Part I): Methods and Results
}

Integrative Cancer Therapies

Volume 19: I-19

(C) The Author(s) 2020

Article reuse guidelines:

sagepub.com/journals-permissions DOI: 10.1 I $77 / 1534735420943278$

journals.sagepub.com/home/ict

(S)SAGE

\author{
Timothy R. N. Holder ${ }^{1,2} \mathbb{D}$, Margaret E. Gruen, DVM, MPH, PhD2, \\ David L. Roberts, PhD $^{2}$, Tamara Somers, PhD $^{3}$, and Alper Bozkurt, MS, PhD ${ }^{1,2}$
}

\begin{abstract}
Animal-assisted interventions (AAls) use human-animal interactions to positive effect in various contexts including cancer care. As the first installment of a 2-part series, this systematic literature review focuses on the research methods and quantitative results of AAl studies in oncology. We find methodological consistency in the use of canines as therapy animals, in the types of high-risk patients excluded from studies, and in the infection precautions taken with therapy animals throughout cancer wards. The investigated patient endpoints are not significantly affected by AAl, with the exceptions of improvements in oxygen consumption, quality of life, depression, mood, and satisfaction with therapy. The AAl field in oncology has progressed significantly since its inception and has great potential to positively affect future patient outcomes. To advance the field, future research should consistently improve the methodological design of studies, report data more completely, and focus more on the therapy animal's well-being.
\end{abstract}

\section{Keywords}

animal-assisted interventions, animal-assisted activities, animal-assisted therapy, oncology, cancer, human-animal bond, quantitative

Submitted April I, 2019; revised June I2, 2020; accepted June 29, 2020

\section{Introduction}

Cancer is the second leading cause of death globally. In 2018, 18.1 million people were newly diagnosed and 9.6 million individuals died from cancer around the world. ${ }^{1}$ As with all potentially chronic diseases, a cancer diagnosis and the subsequent treatment come not only with debilitating physical consequences but also with concomitant psychological distress. Several studies show that the psychological distress from cancer can cause significant problems with adherence to treatment and increase the risk of morbidity and mortality. ${ }^{2-4}$ In cancer and other chronic conditions, if the patients are not treated in a holistic way, conditions can worsen due to diagnosis or treatment side effects in addition to the actual consequences of the disease. While important research is being targeted to the treatment and eradication of the disease, there is a continued need for intervention strategies to address psychological distress and cancer-related side effects. The National Cancer Institute, under the United States' National Institutes of Health, recognizes complementary and alternative medicines as medical products and practices that are not part of standard medical care. Animal-assisted interventions (AAIs) is one complementary treatment of recent interest and is defined as a patient interacting with an animal to improve psychological distress, cancer-related symptoms (eg, pain), and quality of life. ${ }^{5-7}$ AAI refers to a number of activities and is broadly synonymous with terms including pet therapy, animal-facilitated therapy, equine-assisted therapy, and canine-assisted interactions. Though varying definitions abound for most terms in this field, these interventions can be subdivided into 2 categories - animal-assisted activities (AAAs) and animal-assisted therapies (AATs) - that are both relevant to patients with cancer. ${ }^{5-7}$ AAAs are typically a brief,

\footnotetext{
'University of North Carolina and North Carolina State University Joint Department of Biomedical Engineering, Chapel Hill, NC, USA

${ }^{2}$ North Carolina State University, Raleigh, NC, USA

${ }^{3}$ Duke University, Durham, NC, USA

Corresponding Authors:

Timothy Ricardo Nathaniel Holder, University of North Carolina and North Carolina State University Joint Department of Biomedical Engineering, 333 South Columbia Street, Chapel Hill, NC 275I4, USA. Email: trholde2@ncsu.edu

Alper Bozkurt, Electrical and Computer Engineering, North Carolina State University, Raleigh, NC 27606,USA.

Email: aybozkur@ncsu.edu
} 
"meet and greet" animal interaction that improves quality of life in a general sense - for example, students with high stress levels interacting with puppies during an examination week. ${ }^{8}$ AAT typically refers to animal interactions that are structured and deliberately intended to produce a certain clinical outcome - for example, breast cancer survivors riding horses in order to improve muscle quality. ${ }^{9}$ While research efforts have generally shown it to be beneficial or neutral in effect on the patient, most of the evidence for AAI is qualitative, anecdotal, or observational in nature, and rigorous clinical research practices have yet to be widely applied to this work. ${ }^{10-14}$ These problems stem from both lack of theoretical rigor underlying experimental design and inconsistent methodological execution across studies. Relatively little work is done on the effects of AAIs from the animal's perspective. ${ }^{15-18}$ This is ethically relevant if, for example, alleviation of patient stress is necessarily accompanied by increased stress on the therapy animal. In order to better address these issues and validate $\mathrm{AAI}$ as a complementary medicine for cancer patients, the relevant AAIs research must be thoroughly analyzed.

In this first part of a 2-part systematic review of the literature, we focus on the use of quantitative measures to investigate the efficacy of AAIs in oncology. We also focus on the research methodologies used by AAI researchers with special attention paid to participant selection, study design, and research outcomes for both participants and therapy animals. Our overarching goal is to explicate a solid methodological foundation for future work in the field of AAI for oncology patients in order to generate rigorous clinical research studies that lead to wider acceptance and implementation of AAIs. In general, the second article focuses on the proposed mechanisms and theoretical frameworks underlying AAI study design. ${ }^{19}$

\section{Systematic Review Methods}

We conducted a systematic literature review, under the direction of a research librarian, that focused on various terms for both AAI (including animal-facilitated interventions, pet therapy or equine-assisted activities) and cancer (such as neoplasm or oncology). We conducted 3 intermittently spaced preliminary searches from December 2017 to June 2018 to clarify the scope of the field, determine the most relevant databases, draft inclusion criteria for the articles gathered, and refine terms for official Boolean and MeSH searches. The official full literature search was conducted and replicated afterward, gathering any document format from the "beginning of time" to July 31, 2018. We interrogated the PubMed, Web of Science, Scopus, CAB abstracts, CINAHL, Google Scholar, and North Carolina State University, and University of North Carolina-Chapel Hill's library databases for results (Figure 1). Search string inquiries included any permutation of "cancer" and "animal-assisted intervention" (eg, oncology AND pet therapy; cancer AND pet therapy; neoplasms AND animal-facilitated therapy; or neoplasms AND animal-assisted intervention; Supplementary File, available online). Permutations of search terms were found automatically using PubMed's Medical Subject Headings (MeSH) feature and manually entered in non-PubMed databases. These numerous database searches yielded 928 hits in total, which were stored in a citation manager. We then used a deduplication software tool to reduce the results to 452 articles before sorting these again by hand for residual duplicates, culminating in 336 articles. From our preliminary searches, we excluded any articles with little to no potential to contribute to our intended discussion. Particularly, we removed results focused on noncancer conditions such as autism or post-traumatic stress disorder, and results providing no experimental data but rather instructions on how to set up a hospital AAI program. Utilizing these criteria, a first pass reading of titles and abstracts reduced the 336 articles to 54 journal articles and other formats (such as dissertations or online press releases). We further eliminated all formats other than literature reviews, journal articles, conference papers, and dissertations as they all merely pointed to and summarized study results published elsewhere. A full reading of the remaining 49 articles for specific relevance to our review's topic sentence resulted in 32 relevant publications. In this context, relevance is defined as providing independent, novel data, or summary information specifically dealing with the efficacy of AAI and its variants in oncology.

To execute the systematic literature review, the first author conducted the preliminary and official searches, as well as each deduplication effort in concert with a research librarian and the other contributing authors. The first and last authors applied the inclusion and exclusion criteria to the results retrieved from each database. All authors reviewed the final list of articles to be included and contributed significantly to the writing of both parts of this systematic literature review. Through multiple readings of the texts, analysis of the figures, and consultations of supplementary materials, the authors extracted information for this review's section summaries and tabular representations by directly indicating the trends in the data reported by each article's authors. Informed by the GRADE analytical approach, the first author and contributors also specifically reviewed the included articles for crucial limitations or inconsistencies in order to assess the risk of bias for reported outcomes both within each study and across the cancerrelated AAI field as a whole. ${ }^{20-22}$

\section{Systematic Review Results and Discussion}

\section{Methods of AAI Studies in Oncology}

\section{Study Design: Participants}

Study designs. We first consider the study designs represented in the reviewed articles. The work done in this 


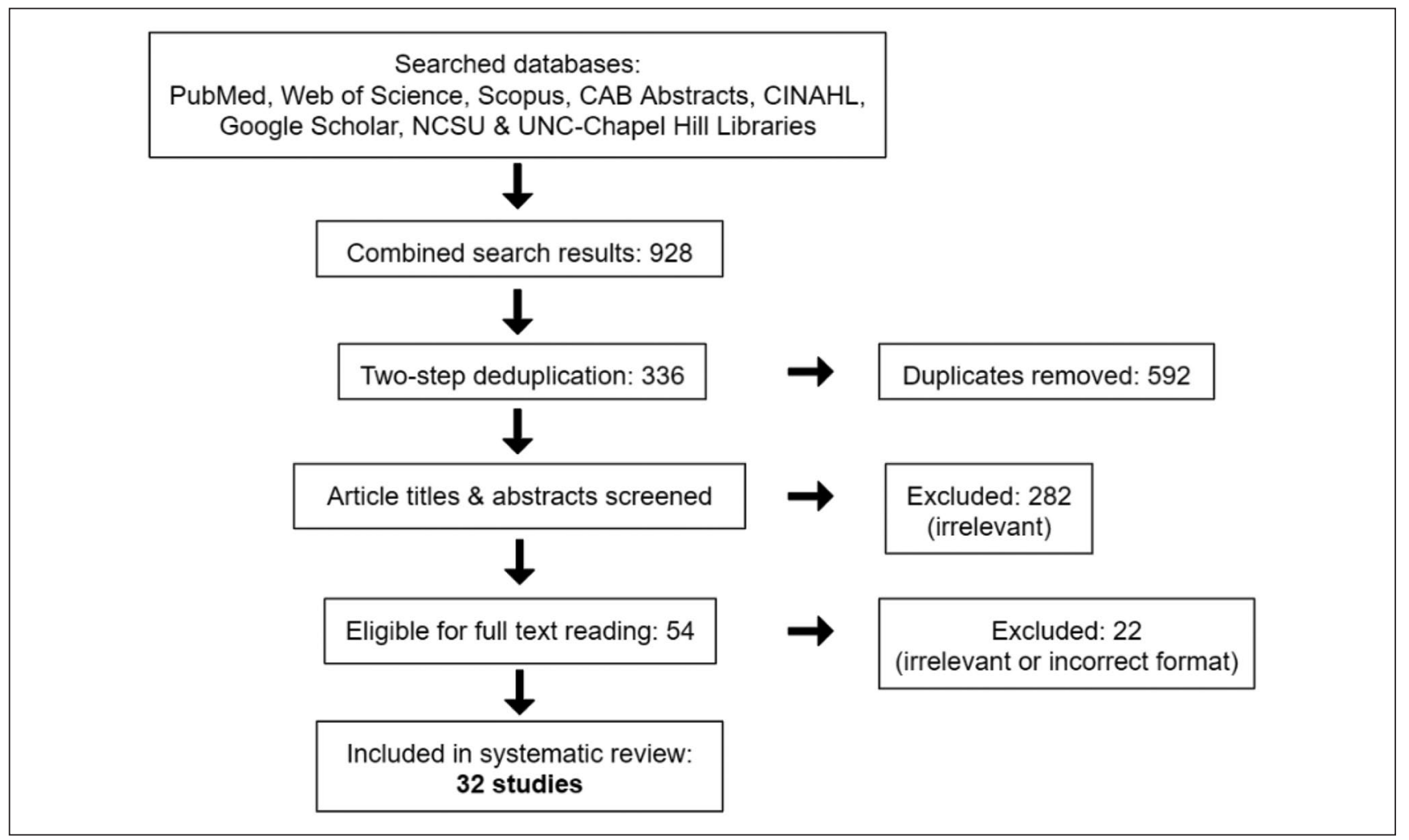

Figure I. Flowchart depicting the article selection process for this review.

section of the AAI field falls into 3 general categories: (1) randomized controlled trials; (2) observational studies with or without controls; and (3) broad, nonintervention surveys (Table 1). In the randomized controlled trials category, the studies by Cerulli et al, ${ }^{9} \mathrm{McCullough}$ et al, ${ }^{23}$ and McCullough et $\mathrm{al}^{24}$ compare intervention group effects to a control condition and randomly assign group membership. The second and largest research class is observational studies further consisting of quasi-experimental studies (8), preto postintervention studies (15), and medical case studies (2). Quasi-experimental studies have both intervention and control groups, but either allow patients to self-select into one of the groups or assign membership using other factors such as recruitment date. ${ }^{7,25-31}$ Pre- to postintervention studies typically collect data before and after either each AAI session or the entire treatment regimen. ${ }^{32-38}$ Some collect data only after the session or treatment is completed, and many may also lack a control condition group. ${ }^{39-46}$ Medical case studies deal with AAI's effect on one patient each and showcase dramatic responses in one patient that may be lost in summary statistics. ${ }^{47,48}$ Both quasi-experimental and preto postintervention studies can provide data suggesting efficacy and highlight potential mechanisms underlying AAI's benefits, while also capturing the subjective experiences of many participants. The third, nonintervention survey class is composed of population surveys that investigate certain
AAI stakeholders (eg, hospital administrators or child life specialists) without actually subjecting the participants to an intervention directly. ${ }^{49-52}$ These surveys of specific populations without intervention allow for closer analysis of attitudes, expectations, and fears surrounding AAIs, while also collecting important data on implementing such programs. The study designs reviewed can also be classified according to their subtype of AAI: AAAs for studies generally improving quality of life and AAT for studies targeted toward achieving a clinically relevant outcome. ${ }^{8}$ Although the reviewed studies often claimed no label at all or adopted one of these 2 labels with varying degrees of accuracy, we used the aforementioned definitions to classify each study in Table 1 for purposes of consistency. These classifications resulted in 13 AAA studies and 16 AAT studies with 3 falling into neither category.

Inclusion and exclusion criteria. One restriction on participant selection in oncology populations is the exclusion of patients who have medical conditions that make the AAI either unsafe or difficult to complete (eg, infection precaution or a recent invasive procedure), who were outside of the desired age ranges, who had an aversion or allergy to the chosen animal, or who could not complete the physical activities or psychological instruments of the study. Most studies also required the handler and therapy animal 
Table I. Study Type and Participant Information for Animal-Assisted Intervention Studies in Oncology.

\begin{tabular}{|c|c|c|c|c|}
\hline Author & Study design; AAl type & Sample size & Age (in years) & Animal type, number, and breed \\
\hline Aiba et $\mathrm{al}^{47}$ & Observational; AAT & I patient & 79 & I dog \\
\hline Bibbo $^{44}$ & Observational; AAA & 34 staff & - & Dogs \\
\hline Bouchard et al ${ }^{39}$ & Observational; AAT & 27 patients $^{\mathrm{a}}$ & Range $=3-16$ & 12 dogs \\
\hline Buettner et $\mathrm{al}^{50}$ & Nonintervention; neither & 75 patients and 5 relatives & Mean $=62.4 ;$ range $=18-87$ & Dogs \\
\hline Caprilli and Messeri ${ }^{46}$ & Observational; AAA & $\begin{array}{l}138 \text { patients, } 46 \text { relatives and } \\
52 \text { staff }\end{array}$ & Mean $=3.5$ & $\begin{array}{l}4 \text { dogs: } 3 \text { Labrador (ages 3, 6, and 8) and } \\
\text { a mixed-breed dog (age 5) }\end{array}$ \\
\hline Cerulli et al ${ }^{9}$ & $\begin{array}{l}\text { Randomized control trial; } \\
\text { AAT }\end{array}$ & 20 patients (control $=10$ ) & Mean $=45.61$ & Horse \\
\hline Chubak et $\mathrm{al}^{32}$ & Observational; AAA & 19 patients $^{\mathrm{b}}$ & $\begin{array}{l}\text { Range }=7-25 ; \text { mean }=12.9(\mathrm{SD} \\
\quad=3.6)\end{array}$ & Dog \\
\hline Chubak and Hawkes $^{49}$ & Nonintervention; AAA & 19 staff & "Pediatric" & Dog, cats, and horses \\
\hline Coakley and Mahoney ${ }^{30}$ & Observational; AAT & $\begin{array}{l}59 \text { patients (noncancer/cancer } \\
\text { patients unspecified) }{ }^{c}\end{array}$ & $\begin{array}{l}\text { Mean }=59.56(S D=15.68) \\
\quad \text { range }=24-88\end{array}$ & Dog \\
\hline Doobrow $^{52}$ & Nonintervention; neither & 12 child life specialists & Range $=18-45$ & Dog \\
\hline Fleishman et $\mathrm{a}^{25}$ & Observational; AAT & 37 patients & Mean $=57.2(\mathrm{SD}=8.44)$ & Dog \\
\hline Gagnon et $\mathrm{al}^{40}$ & Observational; AAT & $\begin{array}{l}16 \text { patients, } 16 \text { relatives and } 12 \\
\text { staff }^{a}\end{array}$ & $89 \%$ between ages of 3 and 13 & Dog \\
\hline Ginex et $\mathrm{al}^{33}$ & Observational; AAT & $\begin{array}{l}100 \text { patients }(\text { control }=50)+ \\
4 I \text { staff }\end{array}$ & $\begin{array}{l}\text { Mean }=55(\mathrm{AFT}) \text { and } 58 \\
\quad(\text { control })\end{array}$ & Dog \\
\hline Haylock and Cantril ${ }^{36}$ & Observational; AAA & 20 patients & Range $=21-79$ & Horse \\
\hline Johnson et $\mathrm{al}^{26}$ & Observational; AAA & $\begin{array}{l}30 \text { patients (human control }=10 \\
\text { and reading control }=10 \text { ) }\end{array}$ & Range $=25-27 ;$ median $=54$ & Dog \\
\hline Johnson et $\mathrm{al}^{27}$ & Observational; AAT & 30 patients & Range $=39-77 ;$ median $=60$ & $\begin{array}{l}2 \text { dogs: I long-haired dachshund and } \\
\text { I whippet }\end{array}$ \\
\hline Kaminski et al ${ }^{28}$ & Observational; AAA & $\begin{array}{l}23 \text { cancer }^{\mathrm{c}} \text { and } 47 \text { other patients } \\
\quad(\text { control }=40)^{\mathrm{b}}\end{array}$ & Mean $=9.86(S D=2.80)$ & Dog \\
\hline Kumasaka et $\mathrm{al}^{34}$ & Observational; AAA & 20 patients & $\begin{array}{l}\text { Mean }=69.45(S D=11.66) ; \text { range } \\
\quad=43-83\end{array}$ & Dogs, cats, and rabbits \\
\hline Larson et $\mathrm{al}^{5 \mathrm{I}}$ & Nonintervention; neither & 309 patients & Range $=19-9 \mid ;$ median $=59$ & Pets \\
\hline Marcus et $\mathrm{al}^{4 l}$ & Observational; AAT & 56 patients & Mean $=59.0 \pm 11.3$ & $\begin{array}{l}\text { I I dogs: medium-large breeds and } \\
\text { mixes }\end{array}$ \\
\hline McCullough et $\mathrm{al}^{23}$ & $\begin{array}{l}\text { Randomized control trial; } \\
\text { AAT }\end{array}$ & 106 patients $(\text { control }=46)^{\mathrm{a}}$ & $\begin{array}{l}\text { Range }=3-17 ;(\text { experimental: } \\
\text { mean }=8.9[\mathrm{SD}=4.5]) \\
(\text { control: } \text { mean }=8.1 \\
[S D=4.6])\end{array}$ & 26 dog-handler teams \\
\hline McCullough et $\mathrm{al}^{24}$ & $\begin{array}{l}\text { Randomized control trial; } \\
\text { AAT }\end{array}$ & 26 therapy teams $^{\mathrm{a}}$ & Range $=2-13$ & $\begin{array}{l}26 \text { dogs: age range }=2-13 \text {; common } \\
\text { breeds: golden retriever }(17 \%), \\
\text { Labrador retriever }(13 \%) \text {, or mixes of } \\
\text { these }(16 \%)\end{array}$ \\
\hline Moreira et $\mathrm{al}^{42}$ & Observational; AAA & 10 relatives and 6 staff & $\begin{array}{l}\text { Range }=4-6 \text { (children), 20-45 } \\
\quad \text { (relatives), and 24-54 (nurses) }\end{array}$ & Dogs \\
\hline Muschel $^{37}$ & Observational; AAT & 15 patients & - & Dogs and cats \\
\hline Orlandi et $\mathrm{al}^{7}$ & Observational; AAA & I 78 patients (control $=89$ ) & $\begin{array}{l}\text { Experimental: mean }=8.9(\mathrm{SD}= \\
4.5) \text { and range }=25-83 ; \text { control: } \\
\text { mean }=8.1(\mathrm{SD}=4.6) \text { and } \\
\text { range }=25-77.5\end{array}$ & $\begin{array}{l}2 \text { dogs: I border collie (age 8) and I } \\
\text { Shetland sheepdog (age 9) }\end{array}$ \\
\hline Petranek et al ${ }^{35}$ & Observational; AAA & 9 patients & - & I dog \\
\hline Phung et $\mathrm{al}^{3 \mathrm{I}}$ & Observational; AAA & $\begin{array}{l}\text { I28 patients (noncancer/cancer } \\
\text { patients unspecified) }{ }^{c}\end{array}$ & $18+$ & $\begin{array}{l}2 \text { dogs: I young black Labrador and I } \\
\text { older giant cockapoo }\end{array}$ \\
\hline Schmitz et al ${ }^{43}$ & Observational; AAT & $\begin{array}{l}47 \text { cancer and } 5 \text { other patients; } 2 \\
\text { handlers }\end{array}$ & $\begin{array}{l}\text { Mean }=63.3 ; \text { range }=28-90 \\
\quad \text { median }=65\end{array}$ & 2 dogs \\
\hline Silva and Osório ${ }^{29}$ & Observational; AAT & 24 patients and 24 staff & Mean $=8.58 ;$ range $=6-12$ & $\begin{array}{l}2 \text { dogs: I Labrador retriever and I } \\
\text { golden retriever }\end{array}$ \\
\hline Toro and del Pilar Valdes ${ }^{38}$ & Observational; AAT & 15 patients & Range $=3-15$ & Unspecified \\
\hline White et $\mathrm{a}^{45}$ & Observational; AAT & 8 patients & Range $=39-61$ & I dog: labradoodle (age 5) \\
\hline Yom $^{48}$ & Observational; AAA & I patient & 54 & I dog: Bichon Frise/poodle (age 7) \\
\hline
\end{tabular}

Abbreviations: AAl, animal-assisted intervention; AAT, animal-assisted therapy; AAA, animal-assisted activities; SD, standard deviation; AFT, animal-facilitated therapy. ${ }^{a}$ Bouchard et $\mathrm{al}^{39}$ and Gagnon et $\mathrm{al}^{40}$ report on the same study. McCullough et $\mathrm{a}^{23}$ and $\mathrm{McCullough}$ et al ${ }^{24}$ report on the same study.

${ }^{\mathrm{b}}$ These studies also collected data from an unspecified number of relatives or staff.

'All studies focused on cancer patients only except for these 4 studies that had both cancer and noncancer patients. 
team to be certified by a reputable organization, to maintain general cleanliness protocols during AAI, to be up-todate on vaccinations, and to submit to regular veterinary checkups. A few studies had additional study criteria worth considering. Bouchard et al, ${ }^{39}$ Caprilli and Messeri, ${ }^{46}$ and Gagnon et $\mathrm{al}^{40}$ each excluded children unable to interact with a dog due to youth (eg, breastfeeding babies) or cognitive disability. In other examples of unique criteria, some research groups required physician approval to participate in the study, ${ }^{9,29,32}$ restricted entrant gender to focus on breast cancer in women, ${ }^{36}$ or selected only participants with conditions requiring multiple hospital visits to ensure a longitudinal study. ${ }^{45}$ Generally, AAI studies shared criteria protecting their participants and differed as needed for their research aims.

Age. The age range of each study's participants are detailed in Table 1. When provided, mean participant ages tended toward older adults (ages 55-75) or younger children (ages 3-12). Adolescent and young adults, as well as middle-aged individuals appear to be underrepresented in AAI research with oncology patients. This research gap may result from difficulty recruiting oncology patients in these age ranges or from difficulties in collecting detailed demographic information in some study designs.

Sample size. Patient recruitment strategies included direct referral from medical staff, solicitation by email or fliers, and selection after reviewing medical records. Cerulli et al, ${ }^{9}$ Larson et $\mathrm{al},{ }^{51}$ and McCullough et a ${ }^{23}$ targeted statistically appropriate numbers of enrollees a priori, obtaining sample sizes of 106,20 , and 309 , respectively. The remaining studies accepted all who met the inclusion criteria and ranged in sample size from $8^{45}$ to $178^{7}$ participants, excluding case studies and nonintervention surveys (Table 1).

Subject type. An important aspect of AAI research design is deciding from whom to collect data as other stakeholders beyond the oncology patient may be in the treatment room. In total, 23 studies gathered data directly from patients, 8 from parents, 10 from medical staff, and 1 from animalhandler teams (Table 1). Even though data collection from the subject of an intervention is paramount, these studies highlight the important perspectives of medical personnel and family members. In 2 special cases, Gagnon et $\mathrm{al}^{40}$ and Schmitz et $\mathrm{al}^{43}$ surveyed parents and handlers, respectively, as proxies for patients too young to provide useful research data. Generally, investigators note the potential of AAI to enhance relationships between patients, caregivers, and other family members, thus necessitating data collection from multiple stakeholders.

Animal selection. Only 13 studies noted the breed, temperament, or number of animals employed in their program; each of these included dogs in their research (Table 1). The most common dog breeds employed were Labrador retrievers and mixes (7 studies), Golden retrievers and mixes (3 studies), and other mixes including neither Labradors nor Golden retrievers (4 studies). AAI studies in oncology generally did not indicate exclusion of therapy animals of any species based on temperament (aside from what would be required for a dog to become certified). With the exception of Ginex et al, ${ }^{33}$ the few canine studies with temperamental preferences opted for calm dogs, hypothesizing that the dogs' mellowness would be beneficial to AAI outcomes. One equine study did specify the use of horses that were calm and gentle. ${ }^{36}$ The number of dogs included in studies ranged from 1 for case studies and studies with smaller participant sample sizes ${ }^{35,45,47,48}$ to 26 dogs for the McCullough et $\mathrm{al}^{24}$ study. This latter study included 60 intervention group participants - even though the largest intervention group serviced 89 participants with 2 dogs. ${ }^{7}$ These results indicate that human sample size does not always determine the number of animals needed in an AAI study. Parameters like longer study durations and fewer visits per patient per week, for example, can allow small numbers of animal-handler teams to service large intervention groups. Since dogs usually work under the supervision of an attending individual, most cancer-related AAI studies use therapy dyads composed of a well-trained dog and his volunteer human owner - both of whom have been certified by an AAI organization (eg, Pet Partners). Of the remaining AAI studies, those that indicate who handles the therapy animals simply employ the pet of the researcher, making the researcher the handler.

\section{Study Design: Parameters}

Controls. Only 9 of the 32 studies used some form of control condition in their work. McCullough et $\mathrm{al}^{23}$ randomly assigned children to control or experimental groups but allowed brief interactions between control condition participants and therapy teams when unavoidable (ie, in waiting rooms or hallways). In the study by Ginex et al, ${ }^{33}$ the investigators observed early in the study that participants in rooms with multiple beds presented practical and ethical concerns for using a control group and altered their design away from a randomized controlled trial. The researchers shifted to a sequential design with data collection from the usual care control group occurring during a specified time block of several weeks before that of the intervention group. Kaminski et $\mathrm{al}^{28}$ also abandoned their initial random group assignment strategy. Since their AAI sessions occurred once weekly, these researchers included pet visitation day study recruits in the intervention group and placed recruits from all other days in the control group. Noting that friendly human interactions may be a source of AAI's benefits, ${ }^{53,54}$ both the Johnson et $\mathrm{al}^{26}$ and Johnson et $\mathrm{al}^{27}$ studies used 2 controls - a reading group and a friendly human group- 
to isolate the dogs' effects on AAI outcomes. Orlandi and colleagues ${ }^{7}$ set up one chemotherapy treatment room with AAI and another without, creating intervention and control groups through participant self-selection. This solution is a modified version of the sequential control group design and risks similar self-selection bias in results. Since the intervention group must travel to horse interaction centers for the physical benefits of equine-assisted therapy, Cerulli and colleagues ${ }^{9}$ avoided cross-contamination concerns by instructing the control group to stay home and avoid new formal exercise programs. Most pre- to postintervention or quasi-experimental studies used the research participants as their own controls. All of these studies highlight the difficulties and considerations researchers deal with when designing AAI research for oncology patients and present some alternative control group strategies to address challenges in this research area.

Intervention location and sample type. On the question of intervention group sample type (ie, individual vs group) and the environment for the intervention, the results in AAI for oncology are mixed (Table 2). For individual AAI sessions, 9 studies conducted the intervention in the patient's hospital room while 4 others moved patients to a designated private space. While only one research cohort used a multi-bed hospital room for group AAI sessions, 9 studies used a designated group space and 4 others hosted sessions in a common waiting area where the therapy animal interacted with all present. Though patient-animal interaction times can vary, the effects of group versus individual AAI protocols remain unclear. Relatedly, conducting AAI in a patient's hospital room may be more convenient than bringing the patient to a different private room. However, designated therapy spaces could provide a useful change of scenery and potentially eliminate negative influences of the patient's hospital room.

Duration and frequency. There was a large degree of variation in duration and frequency of AAI between studies, with a high potential to affect the outcomes. The studies' AAIs range in frequency from 1 session (10 studies) to 32 sessions (1 study) and in duration from around $10 \mathrm{~min}-$ utes ( 5 studies) to 8 to 16 hours ( 1 study; Table 2 ). AAI studies in oncology have had total study durations ranging from 1 month to 3 years. There are no clear patterns within the duration and frequency data, leaving the link between frequency and effectiveness of AAI unclarified. ${ }^{30}$ However, researchers using 10 or more sessions per patient often pointedly classify their work as AAT, implying an intention to produce a certain clinical outcome.

Structured versus unstructured sessions. Beyond session duration and frequency, the majority of studies indicated that participants were free to interact with therapy animals as they wished. However, 5 studies either moderately or strictly structured their participants' animal interactions. Both Muschel ${ }^{37}$ and Schmitz et al ${ }^{43}$ divided their semistructured sessions into 3 blocks of broad activities such as watching or being introduced to the dog, physically playing with or holding the dog, and arranging for another therapy session. Since the study by Silva and Osório ${ }^{29}$ is a group animal interaction study, a set of activities from a predefined list were chosen for each session based on group interests and dynamics. Both strictly structured session designs were for equine-assisted therapy modalities and typical activities included phases of acclimation or bonding, grooming, riding, and education about horses. ${ }^{9,36}$ Structuring AAI sessions ensures a high level of treatment fidelity and reproducibility while permitting researchers and medical staff to better contend with factors such as limited space, patient mobility issues, and infection protocols. Unstructured interactions allow for greater treatment flexibility as participants can choose the level of engagement best for them (eg, playing with a puppy quietly, talking to a therapy horse, or watching a dog perform command tricks).

The study designs found in AAI oncology studies represent a broad range of rigor and theoretical usefulness while adapting to various constraints. While there are wellfounded scientific standards and conventions for research design, hopefully this discussion can be a guide to those trying to discern what type of study will best help them investigate their questions of interest about AAI in oncology and pet therapy more broadly.

\section{Results of AAI Studies in Oncology}

Physiological Endpoints. Since most studies investigated multiple endpoints, often with differing results, this section discusses the efficacy of AAI in oncology according to the physiological or psychological endpoints of interest. This section also discusses trends in each endpoint's results and the devices used for collecting the relevant data.

Heart rate. The most researched physiological parameter is heart rate with the 6 relevant articles showing no consistent trends in results (Table 3). ${ }^{7,9,23,28-30}$ Coakley and Mahoney ${ }^{30}$ and Silva and Osório ${ }^{29}$ saw no significant changes in heart rate. Even though they recorded heart rate throughout riding sessions and pre- to posttreatment, Cerulli et $\mathrm{al}^{9}$ used their heart rate data only to help calculate oxygen saturation maximums in patients (discussed later), noting that a rider's heart rate and oxygen consumption varies with the horse's gait. Kaminski et $\mathrm{al}^{28}$ noted significantly higher heart rates in their study's intervention group both before and after therapy but no significant changes within either the experimental or control groups. The uniformly higher experimental group heart rates are attributed to an anticipatory effect of receiving AAI, to not monitoring heart rate continuously during sessions, and to the 
Table 2. Study Design Information for Animal-Assisted Intervention Studies in Oncology.

\begin{tabular}{|c|c|c|c|c|c|}
\hline Author & Session duration & Frequency & Study duration & Intervention type & Intervention location \\
\hline Aiba et $a l^{47}$ & 15 minutes & $\begin{array}{l}\text { 4/week on weeks I, } 3 \text {, } \\
5 \text {, and } 6 ; 16 \text { total }\end{array}$ & - & Individual & - \\
\hline Bibbo $^{44}$ & $\begin{array}{l}\text { Unspecified (dogs worked } \\
20-90 \text { minutes/visit) }\end{array}$ & 3/week; 12 total & 4 weeks & Individual & $\begin{array}{l}\text { Group and waiting } \\
\text { rooms }\end{array}$ \\
\hline Bouchard et $\mathrm{al}^{39}$ & 8 hours & - & 12 months & Individual & Private room \\
\hline Buettner et $\mathrm{al}^{50}$ & - & - & - & - & Waiting room \\
\hline Caprilli and Messeri ${ }^{46}$ & 2 hours & I/week & 6 months & Group & Group room \\
\hline Cerulli et al ${ }^{9}$ & I hour & 2/week; 32 total & - & Individual & Horse stables \\
\hline Chubak et $\mathrm{al}^{32}$ & $\begin{array}{l}\text { Unspecified (dogs worked } \\
\text { I-2 hours) }\end{array}$ & Various & - & Both & $\begin{array}{l}\text { Private and waiting } \\
\text { rooms }\end{array}$ \\
\hline Chubak et al ${ }^{49}$ & 20 minutes & 1 & 5 months & Individual & Private room \\
\hline Coakley and Mahoney ${ }^{30}$ & 10 minutes & I & $\begin{array}{l}3 \text { years (September } 2004 \\
\text { to July 2007) }\end{array}$ & Individual & Private room \\
\hline Doobrow $^{52}$ & - & - & - & - & - \\
\hline Fleishman et $\mathrm{al}^{25}$ & Mean $=15$ minutes & Mean $=18$ per patient & - & Individual & $\begin{array}{l}\text { Private, group and } \\
\text { waiting rooms }\end{array}$ \\
\hline Gagnon et $\mathrm{al}^{40}$ & $8-16$ hours & $\begin{array}{l}\text { I+ (multiple visits }= \\
\quad 44 \%)\end{array}$ & 12 months & Individual & Private room \\
\hline Ginex et $\mathrm{al}^{33}$ & - & 4/week & - & Individual & Multi-bed room \\
\hline Haylock and Cantril ${ }^{36}$ & - & - & 9 months & Group & Horse stables \\
\hline Johnson et $\mathrm{al}^{26}$ & 15 minutes & 1 & - & Individual & Private room \\
\hline Johnson et $\mathrm{al}^{27}$ & I5 minutes & 3/week; I 2 total & - & Individual & Private room \\
\hline Kaminski et $\mathrm{al}^{28}$ & 90 minutes & I/week & - & Group & Group room \\
\hline Kumasaka et $\mathrm{al}^{34}$ & 30 minutes & $\begin{array}{l}\text { I/month ( } 25 \% \text { had } \\
\text { multiple visits) }\end{array}$ & 2 years & Group & - \\
\hline Larson et $\mathrm{al}^{51}$ & - & - & - & - & - \\
\hline Marcus et $\mathrm{al}^{41}$ & $10-15$ minutes & $\mathrm{I}+$ & $\begin{array}{l}6 \text { months (January } 2012 \\
\text { to June } 2012 \text { ) }\end{array}$ & Individual & - \\
\hline McCullough et $\mathrm{al}^{23}$ & Mean $=24$ minutes & $\begin{array}{l}\text { I/week (sessions per } \\
\text { child: mean }=10.2 \\
\text { and } S D=3.1 \text { ) }\end{array}$ & - & Individual & Semi-/private rooms \\
\hline McCullough et $\mathrm{al}^{24}$ & Mean $=24$ minutes & I/week & - & Individual & Semi-/private rooms \\
\hline Moreira et $\mathrm{al}^{42}$ & I hour & - & $\begin{array}{l}4 \text { months (October } 2014 \\
\text { to February 20I5) }\end{array}$ & Group & Group room \\
\hline Muschel $^{37}$ & I.5 hours & I/week; I0 total & - & Individual & - \\
\hline Orlandi et $\mathrm{al}^{7}$ & 60 minutes & I & $\begin{array}{l}6 \text { months (November } \\
2005 \text { to April 2006) }\end{array}$ & Group & Group room \\
\hline Petranek et al $\left.\right|^{35}$ & $10-20$ minutes & I & Experiment ongoing & Individual & - \\
\hline Phung et $\mathrm{al}^{31}$ & $5-10$ minutes & I & - & Individual & Private room \\
\hline Schmitz et $\mathrm{al}^{43}$ & $\begin{array}{l}\text { Mean }=32.7 \text { minutes } \\
\text { (median }=30 \text { minutes } \\
\text { and range }=10-67 \\
\text { minutes) }\end{array}$ & $\begin{array}{l}\text { Mean }=1.6 / \text { week per } \\
\text { patient; median = I/ } \\
\text { week }\end{array}$ & $\begin{array}{l}\text { II months (June } 2014 \text { to } \\
\text { May 20I5) }\end{array}$ & Individual & Private and group rooms \\
\hline Silva and Osório ${ }^{29}$ & 30 minutes & $3+$ in 4 weeks & $\begin{array}{l}20 \text { months (June } 2015 \text { to } \\
\text { January 20I7) }\end{array}$ & Group & - \\
\hline Toro del Pilar Valdes ${ }^{38}$ & - & - & I month & Individual & - \\
\hline White et $\mathrm{al}^{45}$ & $\begin{array}{l}\text { Unspecified (post- } \\
\text { interview: range = } \\
20-60 \text { minutes) }\end{array}$ & $3+$ & - & Individual & Private room \\
\hline Yom $^{48}$ & - & $2+$ & - & Individual & Private room \\
\hline
\end{tabular}


Table 3. Results of Animal-Assisted Intervention Studies in Oncology.

\begin{tabular}{|c|c|c|c|}
\hline Author & Psychological endpoints & Physiological endpoints & Other endpoints \\
\hline Aiba et $\mathrm{al}^{47}$ & - & - & - \\
\hline Bibbo ${ }^{44}$ & Staff note AAI helped patient QoL & - & $\begin{array}{l}\text { Pet attitude: staff AAI approval }=8.24 \text { (scale of } \\
\text { I-9) and prior perceptions impacted PE }\end{array}$ \\
\hline Bouchard et $\mathrm{al}^{39}$ & - & - & - \\
\hline Buettner et $\mathrm{al}^{50}$ & - & - & - \\
\hline Caprilli and Messeri ${ }^{46}$ & $\begin{array}{l}\text { PE: } 94 \% \text { of parents and } 96 \% \text { of staff } \\
\text { noted AAl helped children }\end{array}$ & - & $\begin{array}{l}\text { Behavioral Coding [SAM: most children very } \\
\text { happy with dog and normal/very happy without; } \\
\text { Behavioral scales: child-animal interaction and } \\
\text { child awareness = above average and child- } \\
\text { environment interaction = average] }\end{array}$ \\
\hline Cerulli et al ${ }^{9}$ & QoL: $\uparrow \uparrow \uparrow$ & O $\mathrm{O}_{2 \uparrow \uparrow \uparrow}$ Sat: $\uparrow \uparrow \uparrow ;$ Muscle strength: & - \\
\hline Chubak et al ${ }^{32}$ & - & - & - \\
\hline Chubak et $\mathrm{al}^{49}$ & $\begin{array}{l}\text { Distress: } \downarrow \downarrow \downarrow \text {; Anxiety: } \downarrow \downarrow \downarrow \text {; } \\
\text { Depression: } \downarrow \downarrow \downarrow \text {; Pain: } \downarrow \downarrow \downarrow \text {; Anger: } \\
\downarrow \text {; PE: majority of staff and children } \\
\text { noted AAI helped }\end{array}$ & - & $\begin{array}{l}\text { Behavioral Coding [Patient and parent behaviors } \\
=\text { generally positive; common acts }=\text { dog tricks } \\
\text { or handler interactions] }\end{array}$ \\
\hline Coakley and Mahoney ${ }^{30}$ & $\begin{array}{c}\text { Mood: } \uparrow \uparrow \uparrow \text {; Pain level: } \downarrow \text {; Energy } \\
\text { level: } \uparrow \text {; Hostility: } \downarrow \downarrow \downarrow\end{array}$ & 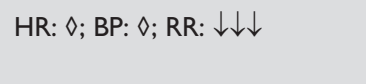 & $\begin{array}{l}\text { Pet ownership: } 47.5 \% \text { (uncorrelated with other } \\
\text { data) }\end{array}$ \\
\hline Doobrow ${ }^{52}$ & - & - & - \\
\hline Fleishman et $\mathrm{al}^{25}$ & $\begin{array}{l}\text { QoL (well-being): [social: } \uparrow \uparrow \uparrow, \\
\text { functional and physical: } \downarrow \downarrow \downarrow \\
\text { and emotional: } \diamond \text { ]; Satisfaction: } \\
\text { [psychological aspects }=\text { high and } \\
\text { physiological aspects }=\text { neutral] }\end{array}$ & - & $\begin{array}{l}\text { Pet attitude: patient affinity for animals }=6.08 \\
\text { (high; range of } I \text { to } 7 \text { ) }\end{array}$ \\
\hline Gagnon et $\mathrm{al}^{40}$ & - & - & - \\
\hline Ginex et $\mathrm{a}^{33}$ & $\begin{array}{l}\text { Anxiety: } \downarrow \downarrow \downarrow \text { (in both groups); } \\
\text { Depression: } \downarrow \text {; Energy level: } \downarrow \downarrow \downarrow\end{array}$ & - & - \\
\hline Haylock and Cantril ${ }^{36}$ & QoL: $\diamond$ & - & - \\
\hline Johnson et $\mathrm{a}^{26}$ & $\begin{array}{l}\text { PE: Both dog group and friendly } \\
\text { human group noted AAI helped }\end{array}$ & - & $\begin{array}{l}\text { Group pet ownership: dog }=50 \% \text {; human }= \\
70 \% \text {; reading = 50\%; (uncorrelated with other } \\
\text { data) }\end{array}$ \\
\hline Johnson et a $\left.\right|^{27}$ & $\begin{array}{l}\text { Mood: } \diamond \text {; Anxiety: } \downarrow \downarrow \downarrow \text { (for all } \\
\text { groups); PH: } \diamond \text {; PE: } 50 \% \text { (Dog } \\
\text { Group), } 90 \% \text { (Friendly Human } \\
\text { Group), and } 60 \% \text { (Reading Group) } \\
\text { note AAl helped }\end{array}$ & - & - \\
\hline Kaminski et $\mathrm{al}^{28}$ & Mood: $\uparrow$ (in both groups) & $\begin{array}{l}\text { HR: } \uparrow \uparrow \uparrow \text {; Cortisol: } \downarrow \text { (in both } \\
\text { groups) }\end{array}$ & $\begin{array}{l}\text { Behavioral Coding [Time showing positive affect: } \\
46 \% \text { (exp) and 19\% (con); Time showing neutral } \\
\text { affect: } 53 \% \text { (exp) and } 81 \% \text { (con); Time showing } \\
\text { positive touching: } 57 \% \text { (exp) and N/A (con)] }\end{array}$ \\
\hline Kumasaka et al ${ }^{34}$ & - & - & $\begin{array}{l}\text { Pet attitude: } 80 \% \text { interested in and } 70 \% \text { liked } \\
\text { pets; pet ownership: } 95 \%\end{array}$ \\
\hline Larson et $\mathrm{al}^{51}$ & - & - & Pet ownership: $55 \%$ \\
\hline Marcus et $\mathrm{al}^{41}$ & $\begin{array}{l}\text { PE: } 98.2 \% \text { of respondents welcome } \\
\text { another AAI visit }\end{array}$ & - & $\begin{array}{l}\text { Pet ownership: } 50 \% \text { (currently) and } 34 \% \\
\text { (previously); pet attitude: } 80 \% \text { liked dogs and } \\
\text { II\% liked cats; (both uncorrelated with other } \\
\text { data) }\end{array}$ \\
\hline
\end{tabular}


Table 3. (continued)

\begin{tabular}{|c|c|c|c|}
\hline Author & Psychological endpoints & Physiological endpoints & Other endpoints \\
\hline McCullough et $\mathrm{al}^{23}$ & $\begin{array}{l}\text { Anxiety: } \downarrow \downarrow \downarrow \text { (in both groups); QoL: } \\
\quad \diamond\end{array}$ & 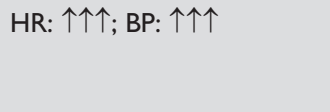 & $\begin{array}{l}\text { Behavioral Coding [Common acts with dog: } \\
\text { petting ( } 92 \%) \text {, talking }(69 \%) \text { and photos }(32 \%) \text { ]; } \\
\text { pet ownership: } 67 \%\end{array}$ \\
\hline McCullough et $\mathrm{al}^{24}$ & - & Cortisol: $\diamond^{\mathrm{a}}$ & $\begin{array}{l}\text { Dog Behavioral Coding [Mean behaviors/session: } \\
9.14 \text { (affiliative), } 9.69 \text { (stress) and } 0 \text { (high stress); } \\
\text { Most coded behaviors/session: oral behaviors } \\
(4.52) \text {, lip licking }(2.31) \text { and tail wagging (I.98); } \\
\text { stress and affiliative behaviors correlated } \\
\text { significantly] }\end{array}$ \\
\hline
\end{tabular}

\begin{tabular}{|c|c|c|c|}
\hline Moreira et $\mathrm{al}^{42}$ & - & - & - \\
\hline Muschel $^{37}$ & - & - & - \\
\hline Orlandi et $\mathrm{al}^{7}$ & $\begin{array}{l}\text { Anxiety: } \downarrow \downarrow \downarrow \text { (in both groups); } \\
\text { Depression: } \downarrow \downarrow \downarrow \text { (in exp group); } \\
\text { Anger: } \downarrow \downarrow \downarrow \text { (in both groups) }\end{array}$ & 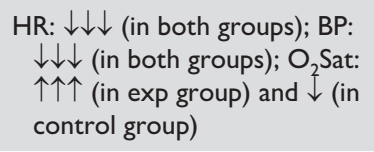 & - \\
\hline Petranek et $\mathrm{al}^{35}$ & QoL: $\uparrow$ & - & - \\
\hline Phung et $\mathrm{al}^{31}$ & $\begin{array}{l}\text { Anxiety: } \downarrow \downarrow \downarrow \text {; Pain level: } \downarrow \downarrow \downarrow \text {; Energy } \\
\text { Level: } \uparrow \uparrow \uparrow ; \text { PE: } 94 \% \text { note AAI } \\
\text { helped }\end{array}$ & - & - \\
\hline Schmitz et $\mathrm{al}^{43}$ & - & - & $\begin{array}{l}\text { Qualitative Content Analysis [most common } \\
\text { act: "stroking the therapy dog"; most common } \\
\text { emotion = "pleasure"]; pet ownership: } 33 \% \\
\text { (currently; dogs = 82\%) and 33\% (previously) }\end{array}$ \\
\hline Silva and Osório ${ }^{29}$ & $\begin{array}{l}\text { Distress: } \downarrow \downarrow \downarrow \text {; Anxiety: } \downarrow \downarrow \downarrow \text {; } \\
\text { Depression: } \downarrow \text {; Pain Level: } \downarrow \downarrow \downarrow \text {; } \\
\text { QoL: } \diamond\end{array}$ & HR: $\diamond ; \mathrm{BP}: \diamond$ & - \\
\hline Toro del Pilar Valdes ${ }^{38}$ & - & - & - \\
\hline White et $\mathrm{al}^{45}$ & - & - & $\begin{array}{l}\text { Pet attitude: } 100 \% \text { dog lovers; pet ownership: } \\
\text { several participants previously owned pets }\end{array}$ \\
\hline Yom $^{48}$ & - & - & - \\
\hline
\end{tabular}

Abbreviations: $\uparrow$, increase; $\uparrow \uparrow \uparrow$, significant increase; $\downarrow$, decrease; $\downarrow \downarrow \downarrow$, significant decrease; $\diamond$, no significant change; AAl, animal-assisted intervention; QoL, quality of Life; $\mathrm{PE}$, perceived effectiveness; $\mathrm{O}_{2}$ Sat, oxygen saturation; HR, heart rate; BP, blood pressure; RR, respiration rate; exp, experiment; con, control; N/A, not applicable. acCullough et $\mathrm{al}^{24}$ measured canine salivary cortisol.

more physically interactive nature of the intervention compared with control activities (eg, reading, puzzles, or video games). Kaminski et $\mathrm{al}^{28}$ also mention that their study did not include a reaction to a stressful event as other studies showing decreased heart rate do. However, Orlandi et $\mathrm{al}^{7}$ also did not include a stressful event, and they note a significant heart rate decrease in both the experimental and control groups; they attribute this and all other positive results to the increased attention the study's participants received from medical staff. In the study by McCullough et al, ${ }^{23}$ the experimental group has significantly higher heart rates after intervention compared with heart rates before. The investigators suggest that this is a product of AAI encouraging physical activity in participants. They also maintain that, while statistically significant, these results are not clinically significant and may indicate increased engage- ment as opposed to an AAI stress response. When obtaining heart rate, standard hospital methods-like counting radial pulse ${ }^{30}$ — are used by most with 2 exceptions. $7,23,28,30$ Cerulli et al $^{9}$ collected heart rate data using a Polar Electro Inc heart rate monitor during exercise measurements and Team System recorder belts from Finland's Polar during horse riding sessions. Silva and Osório ${ }^{29}$ used age-specific BP3ABOH-G-Tech semiautomatic pressure meters throughout their heart rate data collection. The results of studies on heart rate appear to depend somewhat on the nature of the intervention, ranging from vigorous physical activity ${ }^{9}$ to more passively interacting with the animal. ${ }^{7}$ Analysis of heart rate variability sheds light on the emotional states of both humans and canines and, with continuous monitoring, more closely annotates which intervention actions lead to which observed effects. ${ }^{55}$ 
Blood pressure and respiration rate. The second most researched physiological parameter is blood pressure, with the same heart rate studies - excepting Cerulli et al ${ }^{9}$-also looking at this measure (Table 3). ${ }^{7,23,28-30}$ The majority of these studies saw no significant changes in blood pressure $(75 \%)^{23,29,30}$ or did not specify the result of blood pressure measurements $(25 \%){ }^{28}$ Orlandi et $\mathrm{al}^{7}$ alone noted a significant decrease in blood pressure for both control and experimental groups matching that of their heart rate result. Blood pressure data were collected by sphygmomanometer cuff and stethoscope, ${ }^{23,30}$ Dinamap or other standard hospital device, ${ }^{7,23,28}$ or using BP3ABOH-G-Tech semiautomatic pressure meters from G-Tech Scientific Limited. ${ }^{29}$

Respiration rate - a measure related to both heart rate and blood pressure - was only studied by Coakley and Mahoney. ${ }^{30}$ By counting inhalations and expirations for a minute, these researchers observed a significant decrease in respiration rate. Little more can be said for blood pressure or respiration rate in response to AAI for oncology but, similar to patient heart rate, further research is warranted. This is especially true as Orlandi et al, ${ }^{7}$ Coakley and Mahoney, ${ }^{30}$ and other studies have seen significant decreases in these parameters with AAI.

Cortisol. Measuring cortisol is the gold standard of stress detection but, as the analyte must be taken from urine, blood, or saliva, serial measurement during an AAI protocol is troublesome. ${ }^{56-58}$ This may explain why monitoring of cortisol levels is not more common in AAI oncology studies; only 2 of the included studies investigated this analyte. ${ }^{23,28}$ Kaminski et a ${ }^{28}$ observed nonsignificant decreases in salivary cortisol for both the experimental and control groups from a similar pre-AAI starting point. Their collection methodology utilized sterile cups first stored in a freezer before bulk processing in a hospital laboratory. However, the authors also mention that roughly half of their collected pre- and post-therapy samples were lost to evaporation during long-term storage, restricting their data set. As such, the evidence is not strong for AAI's effects on cortisol in patients with cancer.

McCullough et $\mathrm{al}^{24}$ also looked at therapy dog salivary cortisol across 5 medical institutions with AAI programs. Using equipment and analysis provided by Salimetrics LLC, these researchers found no change in the dogs' cortisol concentrations with intervention duration, session frequency, or number of people present during the AAI. Overall, McCullough and colleagues' work suggests that therapy dogs are not significantly stressed during AAI. McCullough et $\mathrm{al}^{24}$ also note that cortisol work with dogs should generally utilize additional animal-focused stress measures to investigate certain behaviors (like yawning or panting) that may alleviate or indicate dog stress otherwise missed in pre- to postintervention collections of analytes.
Other physiological endpoints. Cerulli et $\mathrm{al}^{9}$ looked at body mass index, principal muscle group strength, and maximal oxygen consumption before and after 16 weeks of equine-assisted therapy in breast cancer survivors. Only the intervention group saw significant improvements in any of the 3 categories with average maximal oxygen consumption notably increasing by $28.29 \%$. The authors maintain that these equine-assisted therapy results are similar to those of other physical activity studies with breast cancer survivors. Cerulli and colleagues ${ }^{9}$ measured body mass index using a portable bioelectrical impedance device (Handy 3000; DS Medica) and captured muscle group strength by attaching inertial measurement devices (Free-Power; Sensorize) to resistance training equipment. They also estimated maximal oxygen consumption using heart rate and the AstrandRhyming cycle ergometer test on a model 839E Monark bike from Monark Exercise AB. While their collection methodology is less clear, Orlandi et $\mathrm{al}^{7}$ also note a significant increase in experimental group oxygen saturation while that of the control group decreased, though not significantly. These studies suggest a potential improvement in oxygen consumption over time regardless of AAI therapy animal or session activity level.

\section{Psychological Endpoints and Quantitative Surveys}

Negative emotional states. Several studies investigated AAI's effect on negative emotional states, generally finding significant decreases in anxiety and stress after AAI (Table 3 ). Depression-focused instruments show both reduction and no change. ${ }^{7,23,27,29-33}$ Several studies investigating anxiety with a control condition saw a decrease in both control and experimental groups individually postintervention, but no significant difference between groups. ${ }^{7,23,33}$ The results of Chubak et al ${ }^{32}$ were bifurcated by age with participants younger than 13 years experiencing a greater improvement in effect than older patients. Silva and Osório, ${ }^{29}$ Coakley and Mahoney, ${ }^{30}$ Kaminski et $\mathrm{al}^{28}{ }^{28}$ and Orlandi et $\mathrm{al}^{7}$ showed a significant decrease in depression and improvement in mood - the latter only in the control condition - but Ginex et $\mathrm{al}^{33}$ and Johnson et $\mathrm{al}^{27}$ saw no change in depressive state for any group. ${ }^{7,27-30,33}$ The authors of McCullough et $\mathrm{al}^{23}$ were especially surprised by the lack of a significant difference in negative emotion between the control and experimental groups of their longitudinal study. They posited that the modest reductions observed were still consistent with previous work showing stress decreases as pediatric oncology treatment progresses. The only overall increase in stress was observed in the parents of participants in the McCullough et $\mathrm{al}^{23}$ study. In this article, the stress metrics of the intervention group's parents were slightly lower than the stress of control group parents. None of the studies investigating depression, stress, or anxiety used the same psychological instruments as any other except for Johnson et $\mathrm{al}^{27}$ and Coakley and Mahoney ${ }^{30}$ who both used versions of the Profile of Mood States. Overall, these results indicate that AAI generally 
affects mood states neutrally or positively even if much more investigation is needed to fully clarify these effects.

A few studies also investigated AAI's effect on anger, hostility, and aggressiveness using quantitative surveys. ${ }^{7,27,29,30,32}$ Silva and Osório, ${ }^{29}$ Johnson et $\mathrm{al}^{27}$ and Chubak et $\mathrm{al}^{32}$ found no significant change in hostility before and after their interventions, using the Brunel Mood Scale, the Profile of Mood States, and the PedsQL Present Functioning Scales, respectively. ${ }^{27,29,32}$ Both Johnson et $\mathrm{al}^{27}$ and Silva and Osório ${ }^{29}$ noted that small sample sizes were likely the cause of the lack of statistical significance for their findings. Two studies showed significant decreases in hostility and anger for both control and experimental groups. ${ }^{7,30}$ With a version of the Profile of Mood States, Coakley and Mahoney ${ }^{30}$ observed significant improvements in anger and "many patients called the experience rewarding, happy, very pleasurable, comforting," among other positive comments. Orlandi et $\mathrm{al}^{7}$ found a significant reduction in aggressiveness for their pet therapy group when administering the ADeSsO test (Anxiety, DEpression, Somatic Symptoms, hOstility), a reduced version of other Symptom Questionnaires. ${ }^{59,60}$ However, these researchers also proposed that their pet therapy intervention had little effects on aggression as they noticed a similarly significant reduction in aggression for the control group. Overall, AAIs appear to have a neutral or positive affect on anger, hostility, and aggressiveness in oncology patients.

Other psychological endpoints. A few studies evaluated parameters beyond negative emotional affect, some finding consistent decreases in perceived pain levels with AAI (Table 3). ${ }^{29-31}$ However, investigations into fatigue and energy levels vary, with Coakley and Mahoney ${ }^{30}$ and Phung et $\mathrm{al}^{31}$ finding increases in subject energy, while Ginex et $\mathrm{al}^{33}$ found significant decreases in energy within, but not between their study's experimental and control groups..$^{30,31,33}$ While the duration of Ginex et al's ${ }^{33}$ interventions is unclear, both Coakley and Mahoney ${ }^{30}$ and Phung et $\mathrm{al}^{31}$ had extremely short interventions of 10 minutes or less, which may explain the increased energy in their participants due to the novel burst of canine interaction. Regardless, the relationship between energy levels and AAI is ripe for further investigation. No study used the same instruments to assess subject fatigue or pain, but there was some preference for Likert-type face scales when determining pain levels when determining pain levels in children.

Quality of life and self-perceived health. Six AAI studies in oncology investigated the effects of AAI therapy on quality of life (Table 3). ${ }^{9,23,25,29,35,36}$ Most of these studies found no significant differences after AAI, but Cerulli et $\mathrm{al}^{9}$ noted an increase in quality of life in their equine-assisted therapy participants. This unique result may be due to Cerulli and colleagues working only with women whose cancer was in remission for at least 6 months, ensuring the absence of underlying conditions related to cancer that could significantly affect quality of life measures. Fleishman et $\mathrm{a}^{25}$ only observed that emotional well-being increases when the researchers controlled for concomitant physical well-being decreases. Preliminary analysis of Petranek et al's $\mathrm{s}^{35}$ work shows an improvement in long-term life outlook after participants receive a single art and AAI session. McCullough et $\mathrm{al}^{23}$ and Petranek et $\mathrm{al}^{35}$ used the PedsQLTM and QOLC30/BN20 surveys, respectively, to evaluate cancer patient quality of life, while the remaining studies used versions of the Functional Assessment of Chronic Illness Therapy (FACIT) system. ${ }^{9,25,36}$

Considering the self-perceived health of participants, Johnson et $\mathrm{al}^{26}$ developed an AAI-specific instrument but found no statistically significant correlation between dog visits and self-perceived health. Surveying based on topics from Johnson et al's ${ }^{26}$ instrument, the medical staff in Bibbo $^{44}$ agreed that AAAs should continue and was helpful for their patients' self-perceived health. All of these studies consistently indicate that quality of life and self-perceived health are neutrally or positively affected by AAIs in oncology.

Perceived effectiveness. Many researchers also investigated the perceived effectiveness of AAI using survey questions unique to each study. ${ }^{25-27,29,31,32,41,46}$ Those investigating this parameter found that most all of their participants and other stakeholders were satisfied with the therapy implemented and AAI more broadly. Some participants would even recommend AAI to others in the hospital. ${ }^{29,41}$ Ginex et $\mathrm{a}^{33}$ descriptively analyzed open-ended responses from patients and staff, finding that AAI provided 3 improvements: a sense of happiness or hopefulness, a distraction, and the motivation necessary for recovery. While it is not quantitative data, many AAI studies in oncology also list quotes expressing gratitude to further demonstrate participant satisfaction with AAI. On the whole, perceived effectiveness and satisfaction with AAI therapy is the most positive and the most robustly supported result in AAI oncology studies.

Pet attitudes. Many AAI researchers in oncology asked about pet ownership and attitudes toward pets in order to evaluate the effect these variables had on intervention outcomes. Current and past pet ownership ranged from $47.5 \%{ }^{30}$ to $95 \%{ }^{34}$ of a study's participants but largely had no correlation with or effect on specific AAI outcomes when compared with non-pet owners (Table 3). ${ }^{23,26,30,34,41,43,45}$ Similarly, attitudes toward animals were generally positive with no correlation with the measured parameters, excepting the medical staff in the study by Bibbo ${ }^{44}$ whose previous opinions of AAI affected their perception of its effectiveness. ${ }^{25,34,41,44,45}$ 


\section{Behavioral and Qualitative Coding}

Video-based coding. Beyond physiological measurement and psychological surveys, visual data collection methodology coupled with behavioral coding predominates in AAI studies in oncology (Table 3). ${ }^{23,24,28,32,43,46}$ During AAI sessions, Kaminski et al ${ }^{28}$ recorded video for the first 2 minutes, at 10 minutes, and again at 20 minutes before 3 investigators coded the percentage of time the child displayed different types of affect, time spent on interactive tasks, and amount of touching. When analyzing the video segments, they found that children in the intervention group displayed significantly more positive affect, more touching, and less neutral affect than those in the control condition. Researchers in the study by $\mathrm{McCullough}$ et $\mathrm{al}^{23}$ also video recorded their AAI sessions, noting that pediatric patients mainly petted $(92 \%$ of sessions), talked to $(69 \%)$, and looked at pictures of therapy dogs $(32 \%)$. A related study also recorded the dog's behaviors during AAI sessions with 2 cameras and a 26-point ethogram developed by the study's researchers and animal behavior professionals. ${ }^{23}$ Coding behaviors as affiliative, moderate stress, and high stress, McCullough and colleagues found that equal numbers of moderate stress responses were recorded in each session with no canine displaying any high stress behaviors. Expanding these results, dogs that displayed more stress behaviors also displayed more affiliative behaviors in the same session. McCullough and colleagues showed evidence supportive of cortisol measurement in AAI studies, finding a direct correlation between salivary cortisol levels and displays of stress behaviors in dogs. ${ }^{23}$

Observational coding. In the study by Chubak et $\mathrm{al}^{32} \mathrm{a}$ research assistant used a semistructured form to record all the behaviors of and interactions between the dog and the patient. These researchers found that both patients and parents generally displayed positively coded behaviors throughout, with the most commonly noted interactions being those between the handler and patients, parents, or therapy dogs (ie, dog doing a command trick or handler talking to the parent or patient). Schmitz et al ${ }^{43}$ coupled retrospective analysis with handlers' post hoc write-ups of AAI sessions. These investigators found that pleasure was the most often perceived emotional response, and that the dog enhanced both patient communication and relaxation. Caprilli and Messeri ${ }^{46}$ assessed AAI's effects with independent observers present during the session, with the selfassessment manikin pictorial assessment, and with analysis of participating children's graphic productions. Showing active engagement in the AAI, the behavioral scales completed by observers scored the participants near average in child-environment interactions and above average in both child-animal interaction and level of awareness. Results from the self-assessment manikin showed pediatric participants to be very happy with the dog and normal or very happy without it. Finally, of the 77 children's drawings - thought to be representative of their emotions and feelings $-56 \%$ were animal drawings, confirming the participants' interest in the dogs' presence on the ward. Although all videos recorded were only displayed as art pieces and no definitive results were provided, Petranek et $\mathrm{al}^{35}$ also took pictures of patients' faces before and after treatment to demonstrate AAI's effects. Even though Petranek and colleagues' judgements of the improvement showcased by these photos are necessarily subjective, this research method may be a new source of evidence for AAI's benefits in oncology if coupled with objective image analysis.

Overall, the results of various behavioral coding techniques in AAI studies in oncology show that the most common AAI activity is touching or grooming, that dogs are not visibly highly stressed by AAI, and that patients have generally positive experiences interacting with therapy animals.

Nonintervention Survey Studies. Four studies met this review's inclusion criteria but did not report results of an AAI experiment directly. ${ }^{49-52}$ Asking a convenience sample of oncology patients over 4 days, Buettner et a ${ }^{50}$ found that most people read $(60 \%)$, talk to others $(20 \%)$, play phone games $(5.3 \%)$, or engage in other activities while awaiting treatment, and that anxiety level strongly predicted participants' willingness to participate in AAI. The survey responses indicate that providing communication opportunities $(93 \%)$, mental engagement $(92.3 \%)$, and a means to pass time $(88.8 \%$ ) would be the main benefits of an AAI program if implemented. Chubak and Hawkes ${ }^{49}$ surveyed the top 19 pediatric oncology hospitals with ongoing AAI programs, noting that little is understood about the implementation of AAAs beyond pilot studies and single-site efforts. Focusing on safety, effectiveness, and study design, they found that (1) all programs included dogs, while cats, and miniature horses at one hospital each; (2) most activities took place in outpatient waiting rooms, individual patient rooms, play rooms, or hallways; and (3) 11 sites allowed pediatric oncology patients to participate in AAAs - with one hospital only allowing those cleared under infection control protocols to be involved. Of the sites permitting AAAs for pediatric oncology, all allowed petting of the animal and for the animal to sit on the child's bed with a barrier. In the results by Chubak and Hawkes, ${ }^{49}$ many hospitals also allowed group visits and some even allowed feeding and brushing of the therapy animal. Overall, these investigators conclude that several top hospitals had successfully integrated AAI into their oncology treatment programs by employing strict training certifications, cleanliness protocols, and participant exclusion criteria. In her work, Doobrow ${ }^{52}$ assessed child life specialists' perceptions of AAI's benefits for pediatric oncology patients, arguing that this population is especially vulnerable to stress, anxiety, and the treatment side effects of oncology. 
Utilizing the 12 respondents from an online survey distributed in early 2015, Doobrow ${ }^{52}$ found that 11 thought AAT was generally useful for pediatric oncology, but only 6 believed AAT could be used during treatment procedures. Compared with the survey by Chubak and Hawkes, ${ }^{49}$ Doobrow also found that dogs were the default therapy animal and that the most common interactions were petting, holding, and talking to the therapy animal. In 2009, Larson and colleagues asked 309 tertiary care oncology patients whether they had serious concerns about posthumous care for their pets and if their pets had helped during their oncology treatment..$^{51}$ They found that only a small segment of the whole group (4\%) and of pet owners $(7 \%)$ desired more information on pet care resources, obviating the need for further action. However, Larson and colleagues also found that $45 \%$ of the 170 respondents with pets noted that they felt healthier because of their pet and $48 \%$ of this group also said that their pets helped them deal with stress associated with their diagnosis. In summary, these nonintervention studies compiled important information on patients' interest in, how hospitals currently implement, and how the relevant medical staff perceive AAI programs, while also ensuring that chronically ill patients have fewer unmet pet care needs.

\section{Conclusions and Research Outlook}

\section{Limitations of the State of the Art}

In their critical literature reviews, Stern et $\mathrm{al}^{11}$ and ChurHansen et $\mathrm{al}^{14}$ laid out important methodological changes that could improve our understanding and increase the scientific validity of AAIs. These suggestions included tracking patient and staff attitudes toward animals, randomizing participant group assignments, comparing pets familiar to the patient versus unfamiliar animals, isolating the animal as the crucial experimental variable, ensuring interrater reliability for behavioral and qualitative content coding, and noting times between intervention sessions and survey completion or physical data collection for pre- to postintervention type studies. Although the field of AAI in oncology has progressed significantly since these publications, we discuss additional limitations and general areas of improvement in this section.

As noted previously, researchers use either self-generated questionnaires - which are not always independently validated and can bias results - or existing psychological instruments, but rarely the same survey for the same endpoints across studies. While there are many constraining barriers such as language, age, and study endpoints that justify a different or new instrument, consistent psychological instruments would greatly improve the ability to compare results. Study focus represents a similar field limitation in that AAI researchers are not looking for a common set of generalizable outcomes that systematically advance the state of the art. ${ }^{11}$ This lack of study focus consensus also creates issues with data recording and protocol reporting as individual studies may not collect information relevant to the field generally. For example, details such as the number and type of dogs included or the duration and frequency of interventions, if not reported, can severely weaken a result's generalizability.

Addressing a different issue, some researchers note when AAIs are occurring during treatment (eg, before radiation therapy, after surgery, 6 months posttreatment, or in the first 4 weeks of diagnosis) while others neglect to do so. ${ }^{9,27,33}$ For example, Coakley and Mahoney ${ }^{30}$ collected patient data both at the beginning of their hospitalization and while others were getting ready for discharge, suggesting that they may have observed stronger responses if all participants received AAI at the peak of their illness. Both Johnson et $\mathrm{al}^{27}$ and McCullough et $\mathrm{al}^{23}$ explicitly note that severity of cancer symptoms or type of treatment can affect how researchers should interpret study results. Not tracking these variances in disease or treatment progression makes results very difficult to directly compare across studies and generates an aura of one-off studies rather than repeatable, reliable work. Recruiting patients for AAI also presents a challenge as most studies do not control for either the selfselection of dog lovers to participate or for the respondents to be those with the most exaggerated experiences, positive or negative. ${ }^{34}$ Other articles struggle to account for or completely ignore the potential effects that handlers, parents, and other people in the room could have on results. ${ }^{61}$ Johnson et $\mathrm{al}^{27}$ also note that cross-contamination of members in experimental and control groups when in waiting or treatment rooms could affect results.

Research efforts could benefit greatly from longer recording periods and real-time, continuous monitoring of participants with physiological monitoring devices before, during, and after AAIs. These would provide information on the long-term effects of AAI and on which activities lead directly to which physiological or behavioral responses. For example, a pilot study published by Foster et al ${ }^{62}$ used custom wearable systems on both human and canine participants to evaluate the effects of a brief clinical AAI. The system presented in this work collected data for the entire intervention duration that, theoretically, could be directly correlated with specific session activities post hoc. Novel work is on the horizon; Di Nardo et $\mathrm{a}^{63}$ describe efforts to decrease cortisol collection times for dogs, which would allow this variable to be measured more efficiently. Also, Aoki et $\mathrm{al}^{64}$ describe an effort to measure AAI's effects on brain activity with near-infrared spectroscopy. These novel techniques may also bolster the amount of detailed information provided by AAI studies. ${ }^{63,64}$ The AAI field in oncology also does not closely track other concurrent interventions and complementary medical treatments (eg, psychological 
counseling, acupuncture, or therapeutic touch) that could affect long-term AAI results. For example, McCullough et $\mathrm{al}^{23}$ explicitly state that they did not collect data on covariates or other comorbidities that could have affected the endpoints of interest. Aiba et $\mathrm{al}^{47}$ and Fleishman et $\mathrm{al}^{25}$ are notable exceptions, and both track other medical treatments coinciding with their study interventions. However, these researchers mention that they are only interested in measuring a "common complementary therapy option as it readily occurs in these settings" rather than in completely isolating the animal-assisted interaction's effects.

In relation to self-reported data, $\mathrm{Bibbo}^{44}$ discussed the Hawthorne effect, where subjects modify behavior when aware of their being observed. While it was not a significant factor in that work, the AAI field in oncology should seek ways to control or eliminate this potentiality. For various reasons, many studies excluded participants who could still benefit from a complementary or alternative medical therapy similar to AAI without the concomitant risks and complications (eg, zoonotic infection risks, aversion to dogs, or allergic reactions to cats). Future research efforts should explore the use of modified protocols, hypoallergenic animals, robotic pets, and even remote animal interaction setups in order to reach these excluded populations. ${ }^{65,66}$ Generally, researchers should take number, breed, and temperamental information into account when selecting animals and designing studies for optimal AAI outcomes. Several studies mentioned that larger sample sizes would have provided better results and more noticeable effect sizes. ${ }^{25-27,30,43,50,52}$ Like McCullough et $\mathrm{al}^{23}$ and Larson et $\mathrm{al},{ }^{51}$ future researchers should perform a priori statistical analyses of the sample sizes and other numeric parameters needed to provide robust data about the AAI phenomenon of interest. Finally, while most researchers allowed for unstructured interactions with therapy animals, future studies should also implement reasonably structured sets of activities in order to investigate which produce the greatest responses and to evaluate the merits of structured sessions.

The AAI field also has nonmethodological limitations that can affect experimentation and results. The first is the field's general imprecision in the use of terms. Many others have noted that AAAs, AAIs, AAT, animal-facilitated therapy (AFT), pet therapy, and all of the variations with "canine" or "equine" inserted throughout are used sporadically, interchangeably, and nonspecifically despite some efforts to formalize the language in the field. ${ }^{11,14,67-69}$ In creating Table 1, we experienced some difficulty when attempting to strictly reclassify the studies included in this review according to AAA or AAT as several articles did not provide sufficient information about the aims of their work. The article gathering portion of the literature review process was also much more complex due to the numerous and inconsistent terms used as keywords for AAI studies. Even if these terms have slightly different meanings, the nuances ought to be fully elucidated and agreed on to solidify the field's theoretical basis and facilitate better communication of results. Furthermore, as the field evolves so will the experimental and treatment goals of researchers, possibly making it necessary to further subdivide the terminology beyond AAA and AAT.

Another unique and persistently problematic limitation of the AAI field is the tendency to ignore the therapy animal's perspective and the potential effects that AAI can have on them. In oncology, only 4 of 32 AAI articles investigated any effect on the therapy animal ${ }^{23,27,29,43}$ with one other article briefly mentioning taking steps to ensure that "therapy dogs did not show any signs of stress during the study." 46 Although most studies recruit from nationally recognized organizations, universal standards for human-animal interactions should always be followed, including important practices like regular veterinary screenings and ensuring the constant availability of a trained professional who is knowledgeable about animal well-being. ${ }^{5}$ Beyond the important ethical principle of doing no harm, the quality of care delivered can be significantly affected by both the mental and physical state of the participating animal. Similar to other subfields of AAI, oncology can be stressful and researchers should monitor the effects on the animal very closely. Currently, animal welfare is monitored largely either by preto postintervention cortisol measurements or video analysis of canine stress behaviors, but additional methods of assessing this important component of AAI are worth exploring. ${ }^{70}$

AAI in oncology and the AAI field in general has a potential crucial limitation in the types of animals chosen. While there are good reasons for defaulting to dogs (eg, many humans are already quite familiar with dogs, they are already well integrated into many hospitals, and they tend to have suitable temperaments for AAI), dogs are overrepresented - almost to the exclusion of any other living being - among animals employed in AAI. Assuming different animals have different characteristics, diversity in this area could broaden AAI's range of positive effects. This is well demonstrated in the equine-assisted therapy articles where the authors note special benefits due to bonds formed while riding the horses; features understandably absent from the human-canine bond. ${ }^{9,36}$ While considering patient preference, some participants in the Phung et $\mathrm{al}^{31}$ study requested that cats be used rather than dogs; welfare effects for cats would need to be closely monitored, however. Diversifying the animal pool within reason could also ameliorate the issues of excluding those humans who are allergic or have an aversion to dogs. Finally, studying animals other than dogs can better allow researchers to make broadly valid claims about AAIs, rather than generalizing from one test animal to all other cases.

While many articles make a point to track infections and exclude those with fear of the chosen therapy animal, not much is understood about the potential negative effects of AAI for humans. Although initially hard to conceive, 
Table 4. Risk of Bias Across Outcomes for Animal-Assisted Intervention Studies in Oncology .

\begin{tabular}{|c|c|c|c|}
\hline Outcome & Low & Moderate & High \\
\hline Heart rate & Cerulli et $\mathrm{al}^{9}$ & $\begin{array}{l}\text { Coakley and Mahoney }{ }^{30} ; \text { McCullough } \\
\text { et } \mathrm{a}^{23} ; \text { Orlandi et } \mathrm{al}^{7} ; \text { Silva and } \\
\text { Osório }^{29}\end{array}$ & Kaminski et $\mathrm{al}^{28}$ \\
\hline Blood pressure & - & $\begin{array}{l}\text { Coakley and Mahoney }{ }^{30} ; \text { McCullough } \\
\text { et } \mathrm{al}^{23} ; \text { Orlandi et } \mathrm{al}^{7} ; \text { Silva and } \\
\text { Osório }^{29}\end{array}$ & Kaminski et $\mathrm{a}^{28}$ \\
\hline Respiration rate & - & Coakley and Mahoney ${ }^{30}$ & - \\
\hline Cortisol & McCullough et $\mathrm{a}^{24}$ (canine) & McCullough et $\mathrm{al}^{23}$ & Kaminski et $\mathrm{al}^{28}$ \\
\hline Oxygen saturation & Cerulli et al ${ }^{9}$ & Orlandi et $\mathrm{al}^{7}$ & - \\
\hline $\begin{array}{l}\text { Mood (anxiety, stress, and } \\
\text { depression) }\end{array}$ & Chubak et $\mathrm{al}^{32}$ & $\begin{array}{l}\text { Coakley and Mahoney }{ }^{30} \text {; Ginex } \\
\text { et } \mathrm{al}^{33} ; \text { Johnson et } \mathrm{al}^{27} \text {; Kumasaka } \\
\text { et } \mathrm{al}^{34} ; \text { McCullough et } \mathrm{a}^{23} \text {; } \\
\text { Muschel } \mathrm{I}^{37} \text {; Orlandi et } \mathrm{al}^{7} \text {; Silva and } \\
\text { Osório }{ }^{29}\end{array}$ & $\begin{array}{l}\text { Buettner et } \mathrm{al}^{50} \text {; Kaminski } \\
\text { et } \mathrm{al}^{28} \text {; Phung et } \mathrm{al}^{31} \text {; Toro } \\
\text { et } \mathrm{al}^{38}\end{array}$ \\
\hline Anger/hostility/aggression & Chubak et a $\left.\right|^{32}$ & Orlandi et al ${ }^{7}$ & - \\
\hline Pain/fatigue/energy & Cerulli et al ${ }^{9}$; Chubak et al ${ }^{32}$ & Coakley and Mahoney ${ }^{30}$; Ginex et $\mathrm{al}^{33}$ & Buettner et $\mathrm{a}^{50}$; Phung et $\mathrm{al}{ }^{31}$ \\
\hline Quality of life & - & $\begin{array}{l}\text { Fleishman et } \mathrm{al}^{22} \text {; McCullough et } \mathrm{al}^{23} \text {; } \\
\text { Petranek et } \mathrm{al}^{35} ; \text { Silva and Osório }\end{array}$ & Haylock and Cantrii ${ }^{36}$ \\
\hline Perceived effectiveness & - & $\begin{array}{l}\text { Bibbo }{ }^{44} \text {; Caprilli and Messeriiti } \\
\text { Chubak et a }{ }^{32} \text {; Johnson et } \mathrm{a}^{26}\end{array}$ & $\begin{array}{l}\text { Gagnon et } \mathrm{al}^{40} ; \text { Marcus } \\
\text { et al }{ }^{41} ; \text { Moreira et al }{ }^{42}\end{array}$ \\
\hline Perceived health & - & Johnson et $\mathrm{al}^{27}$ & \\
\hline Pet attitudes/ownership & - & $\begin{array}{l}\text { Kumasaka et al }{ }^{34} \text {; Schmitz et al }{ }^{43} \text {; } \\
\text { White et } \mathrm{al}^{45}\end{array}$ & Bibbo ${ }^{44}$; Marcus et $\mathrm{al}^{41}$ \\
\hline Video coding/recording & McCullough et a ${ }^{24}$ (canine) & McCullough et $\mathrm{al}^{23}$ & - \\
\hline $\begin{array}{l}\text { Observation/observational } \\
\text { coding }\end{array}$ & - & Caprilli and Messeri ${ }^{46}$ & Aiba et $\mathrm{al}^{47} ; \mathrm{Yom}^{48}$ \\
\hline Other & $\begin{array}{l}\text { Cerulli et } \mathrm{al}^{9} \text { (fat mass } \% \text {, total body water } \\
\% \text {, strength of principal muscular groups); } \\
\text { McCullough et } \mathrm{al}^{24} \text { (C-BARQ for canines) }\end{array}$ & $\begin{array}{l}\text { Schmitz et al }{ }^{43} \text { (qualitative content } \\
\text { analysis); White et } \mathrm{a}^{45} \text { (qualitative } \\
\text { content analysis) }\end{array}$ & - \\
\hline
\end{tabular}

${ }^{a}$ Though the risk of bias scores of the included studies are displayed by outcome, the studies within each outcome group did not have the same directionality or significance of data.

examples of negative AAI effects could include a subject's heart racing above safe levels or a subject suffering a deeper depression on cessation of the AAI program and thus the loss of their new animal friend. A version of the latter effect is implied by a terminal cancer patient in Muschel $^{37}$ : "I've always had animals in my life. I love them. But I don't want one now because I would want to take it home with me and I'm not going home." Coupled with the lack of focus on the dog (negative and positive outcomes), ignoring negative effects on humans could mean that researchers may only be getting part of the complete AAI picture; this is without even mentioning other stakeholders such as family or medical staff. A fair rejoinder is that most of the psychological instruments used are already sensitive to potential AAI downside and that a simple discussion of their results is adequate to detect any negative psychological responses. However, we observe that this is truer in theory than in practice. When physiological or psychological results are aberrant or paradoxical, they are often not interpreted by researchers as negative consequences of AAI but rather attributed to other factors. When working with humans, hospitals, and complex conditions like cancer, it is already sufficiently difficult to know which effects are direct outcomes of AAI. Thus, individual studies and the field as a whole could benefit from neutral experimental designs geared toward collecting potentially negative effects, as well as positive outcomes. It is important to state that a reliable finding of negative aspects to AAI in oncology-for example, the well-known risk of infection - is not fatal to the field. Future participants can simply be advised of the risks and side effects of pet therapies before making a well-informed decision about this complementary treatment option.

Due to the limitations detailed in this section, the authors of this literature review found that most outcomes in cancer-AAI are supported by studies with moderate to high risk of bias, as others in the field have previously mentioned (Table 4) ${ }^{11,14}$ Notable exceptions include the Cerulli et al, ${ }^{9}$ McCullough et al, ${ }^{23}$ and McCullough et al, ${ }^{24}$ and Chubak 
et $\mathrm{al}^{32}$ studies whose results are supported by more rigorous experimental approaches. Going forward, there are too few higher quality studies with comparison or control groups to permit confident assertions about overall effects of AAIs on cancer patients; especially as some outcomes are better supported than others. However, the AAI research completed in oncological contexts so far suggests several potential benefits to cancer patients. These studies can serve as useful guidance for future studies better able to support the field's broader claims by addressing its common limitations. Additionally, treatment with these types of complementary interventions can still be informed by the larger body of evidence supporting positive effects for medical AAIs or that for nonclinical human-animal interactions more generally. For example, although the results of studies mentioned in their review were also mixed, a meta-analysis conducted by Waite et $\mathrm{al}^{71}$ found that AAI can effectively result in "large changes in pain, distress, and anxiety."

\section{This Review's Limitations}

While we endeavored to provide a comprehensive picture of quantitative measures used for investigating the efficacy of AAIs in oncology, our systematic literature review has implicit and explicit limitations. Although our inclusion and exclusion criteria were based on several preliminary searches, it is possible that, due to our definitions and keywords, a relevant article was excluded or an unrepresentative article included. To illustrate this point, studies meeting the "oncology" criterion had to explicitly list at least one patient in the study who was diagnosed with cancer. However, large AAI studies may exist that included cancer patients without explicitly providing a list of participant medical conditions. Alternately, in some included studies, cancer did not constitute all or even a majority of the participants' diagnoses. ${ }^{28,30,31,43}$ This latter issue especially may decrease some of the specificity that the included results have when assessing AAI's efficacy in oncology. Additionally, while we did not exclude articles based on country of origin, limiting the reviewed articles to those published in English (or with English translations) may have effectively had this disparate outcome. We are aware of 3 potentially relevant articles, one from Konigorski et al, ${ }^{72}$ Andreu et al, ${ }^{73}$ and Borgatti et al, ${ }^{74}$ that were excluded for linguistic reasons. This work also aims to use AAI in oncology as a lens to better understand the human-animal bond more broadly. However, some results are not generalizable to all other AAI cases with or without cancer. For example, the overwhelming majority of the cited AAI studies in oncology use dogs only, introducing the possibility that the results summarized are more representative of canine-assisted interventions than $\mathrm{AAI}$ as a whole. While we can make certain pronouncements based on the research reviewed herein, those conclusions may not be applicable to other human-animal bonds (eg, bonds with military dogs or bonds with race horses) or even to other kinds of AAIs (eg, AAI for post-traumatic stress disorder or AAI for autism).

\section{Summary and Conclusion}

In this article, we presented the results of a systematic literature review evaluating the designs and efficacy of AAI studies in oncology through quantitative metrics. We found that researchers have little to no consistency across experimental methodologies other than preferring temperamentally calm dogs to be therapy animals, excluding extremely high-risk patients, and enforcing practical hygienic standards for therapy teams. Most studies were observational and employed pre- to postintervention or quasi-experimental study designs; however, a few researchers conducted randomized controlled trials. Studies often investigated groups at the extremes of the age spectrum with adolescents, young adults, and middle-aged populations being underserved. Most studies preferred either individual or group AAI sessions composed of unstructured activities, and we found no patterns in the session durations and frequencies used across studies. Though there is considerable variation across studies, researchers in cancer-related AAI have generally chosen research designs that isolate the outcomes of interest and provide results useful for decisionmaking in cancer care.

The results of these studies in oncology showed that AAIs generally have a neutral, sometimes positive, association with the physiological and psychological endpoints of interest. Specifically, oxygen saturation increased, quality of life improved, perceived satisfaction with AAI was high, and depression and other negative mood states decreased among research participants. Most, if not all, other variables - both physiological (eg, heart rate, blood pressure, respiration rate, and cortisol) and psychological (eg, anxiety, distress, hostility, self-perceived health, and quality of life)-investigated across studies showed no significant changes with AAI. In some studies, behavioral coding from recorded videos and direct observation showed that stroking the therapy animal was the most common affiliative session behavior and that the animals involved displayed no or few high stress behaviors. Patients, relatives, and medical staff all generally viewed AAI as helpful in oncology, and a majority would recommend or welcome future animal visits. Many of the aforementioned stakeholders held positive opinions of animals or owned pets at some time, though neither parameter correlated with any other study data. Overall, the evidence for AAI's benefits in oncology is promising but requires more support from well-designed studies (eg, randomized controlled trials.) As a therapeutic modality, the observed benefits of AAI are likely to be context dependent. If true, this would necessitate the personalization of animal-assisted treatments to individual patients 
and environments in order to elicit the positive outcomes desired. ${ }^{31}$ As the effects of certain therapy animals, intervention procedures, and treatment environments are better understood for cancer patients and communication among researchers in the field continues to increase, an authoritative modular protocol may be possible. This would permit medical staff to take or leave the components that meet their patients' needs while preserving validity and comparability across published studies. Improved data reporting (eg, tracking comorbidities), unification of field terminology, and attentiveness to therapy animal well-being are additional suggestions that can greatly advance the state of the art.

The second part of this 2-paper systematic literature review focuses on the mechanisms and theoretical frameworks proposed by researchers in oncological AAI. ${ }^{19}$ The detailed discussion herein seeks to be a guide for researchers investigating the topic of AAI in oncology and animal therapies more broadly. In time, AAIs will be a well-validated complementary treatment, with greater understanding of the impact on patient health and well-being.

\section{Acknowledgments}

The authors would like to acknowledge the contribution of Robert Capaldo to this article.

\section{Declaration of Conflicting Interests}

The author(s) declared no potential conflicts of interest with respect to the research, authorship, and/or publication of this article.

\section{Funding}

The author(s) disclosed receipt of the following financial support for the research, authorship, and/or publication of this article: The authors acknowledge support from the United States National Science Foundation through CCSS-1554367, ECC-1160483, and IIS-1329738. This material is also based upon work supported by IBM Faculty Awards.

\section{ORCID iD}

Timothy Ricardo Nathaniel Holder (iD https://orcid.org/0000 $-0002-6788-9970$

\section{Supplemental Material}

Supplemental material for this article is available online.

\section{References}

1. Bray F, Ferlay J, Soerjomataram I, Siegel RL, Torre LA, Jemal A. Global cancer statistics 2018: GLOBOCAN estimates of incidence and mortality worldwide for 36 cancers in 185 countries. CA Cancer J Clin. 2018;68:394-424. doi:10.3322/ caac. 21492

2. Love RR, Leventhal H, Easterling DV, Nerenz DR. Side effects and emotional distress during cancer chemotherapy. Cancer. 1989;63:604-612.doi:10.1002/1097-0142(19890201)63:3<604::AIDCNCR2820630334>3.0.CO;2-2
3. Faller H, Schuler M, Richard M, Heckl U, Weis J, Küffner $\mathrm{R}$. Effects of psycho-oncologic interventions on emotional distress and quality of life in adult patients with cancer: systematic review and meta-analysis. J Clin Oncol. 2013;31:782793. doi:10.1200/JCO.2011.40.8922

4. VanHoose L, Black LL, Doty K, et al. An analysis of the distress thermometer problem list and distress in patients with cancer. Support Care Cancer. 2015;23:1225-1232. doi:10.1007/s00520-014-2471-1

5. International Association of Human-Animal Interaction Organizations. The IAHAIO definitions for animal assisted intervention and guidelines for wellness of animals involved. IAHAIO White Paper. Published 2014. Accessed January 21, 2019. http://iahaio.org/wp/wp-content/uploads/2017/05/ iahaio-white-paper-final-nov-24-2014.pdf

6. Pet Partners. Terminology. Accessed March 28, 2019. https:// petpartners.org/learn/terminology/

7. Orlandi M, Trangeled K, Mambrini A, et al. Pet therapy effects on oncological day hospital patients undergoing chemotherapy treatment. Anticancer Res. 2018;27(6C): 4301-4303.

8. Haubenhofer DK, Kirchengast S. Dog handlers' and dogs' emotional and cortisol secretion responses associated with animal-assisted therapy sessions. Soc Anim. 2007;15:127150. doi:10.1163/156853007X187090

9. Cerulli C, Minganti C, De Santis C, Tranchita E, Quaranta F, Parisi A. Therapeutic horseback riding in breast cancer survivors: a pilot study. J Altern Complement Med. 2014;20:623629. doi:10.1089/acm.2014.0061

10. Kazdin AE. Methodological standards and strategies for establishing the evidence base of animal-assisted therapies. In: AH Fine, ed. Handbook on Animal-Assisted Therapy: Foundations and Guidelines for Animal-Assisted Interventions. Elsevier; 2015:377-390. doi:10.1016/b978-012-801292-5.00027-4

11. Stern C, Chur-Hansen A. Methodological considerations in designing and evaluating animal-assisted interventions. Animals (Basel). 2013;3:127-141. doi:10.3390/ani3010127

12. Bert F, Gualano MR, Camussi E, Pieve G, Voglino G, Siliquini R. Animal assisted intervention: a systematic review of benefits and risks. Eur J Integr Med. 2016;8:695-706. doi:10.1016/j.eujim.2016.05.005

13. Morrison ML. Health benefits of animal-assisted interventions. $J$ Evid Based Integr Med. 2007;12:51-62. doi:10.1177/1533210107302397

14. Chur-Hansen A, McArthur M, Winefield H, Hanieh E, Hazel $\mathrm{S}$. Animal-assisted interventions in children's hospitals: a critical review of the literature. Anthrozoos. 2014;27:5-18. doi:10. 2752/175303714X13837396326251

15. Glenk LM, Kothgassner OD, Stetina BU, Palme R, Kepplinger B, Baran H. Therapy dogs' salivary cortisol levels vary during animal-assisted interventions. Anim Welf. 2013;22:369-378. doi:10.7120/09627286.22.3.369

16. Glenk LM, Kothgassner OD, Stetina BU, Palme R, Kepplinger B, Baran H. Salivary cortisol and behavior in therapy dogs during animal-assisted interventions: a pilot study. $J$ Vet Behav. 2014;9:98-106. doi:10.1016/j.jveb.2014.02.005

17. Glenk LM. Current perspectives on therapy dog welfare in animal-assisted interventions. Animals (Basel). 2017;7:7. doi:10.3390/ani7020007 
18. Beerda B, Schilder MBH, Janssen NSCRM, Mol JA. The use of saliva cortisol, urinary cortisol, and catecholamine measurements for a noninvasive assessment of stress responses in dogs. Horm Behav. 1996;30:272-279. doi:10.1006/ hbeh.1996.0033

19. Holder TRN, Gruen ME, Roberts DL, Somers TJ, Bozkurt A. A systematic literature review of animal assisted interventions in oncology (part II): theoretical mechanisms and frameworks. Integr Cancer Ther. 2020. doi.org/10.1177/1534735420943269

20. Balshem H, Helfand M, Schünemann HJ, et al. GRADE guidelines: 3. Rating the quality of evidence. JClin Epidemiol. 2011;64:401-406. doi:10.1016/j.jclinepi.2010.07.015

21. Guyatt GH, Oxman AD, Vist G, et al. GRADE guidelines: 4. Rating the quality of evidence-study limitations (risk of bias). J Clin Epidemiol. 2011;64:407-415. doi:10.1016/j. jclinepi.2010.07.017

22. Guyatt GH, Oxman AD, Montori V, et al. GRADE guidelines: 5. Rating the quality of evidence-publication bias. $J$ Clin Epidemiol. 2011;64:1277-1282. doi:10.1016/j. jclinepi.2011.01.011

23. McCullough A, Ruehrdanz A, Jenkins MA, et al. Measuring the effects of an animal-assisted intervention for pediatric oncology patients and their parents: a multisite randomized controlled trial. J Pediatr Oncol Nurs. 2018;35:759-177. doi:10.1177/1043454217748586

24. McCullough A, Jenkins MA, Ruehrdanz A, et al. Physiological and behavioral effects of animal-assisted interventions on therapy dogs in pediatric oncology settings. Appl Anim Behav Sci. 2018;200:86-95. doi:10.1016/j.applanim.2017.11.014

25. Fleishman S, Homel P, Chen M, et al. Beneficial effects of animal-assisted visits on quality of life during multimodal radiation-chemotherapy regimens. J Community Support Oncol. 2015;13:22-26. doi:10.12788/jcso.0102

26. Johnson RA, Meadows RL, Haubner JS, Sevedge K. Humananimal interaction: a complementary/alternative medical (CAM) intervention for cancer patients. Am Behav Sci. 2003;47:55-69. doi:10.1177/0002764203255213

27. Johnson RA, Meadows RL, Haubner JS, Sevedge K. Animalassisted activity among patients with cancer: effects on mood, fatigue, self-perceived health, and sense of coherence. Oncol Nurs Forum. 2008;35:225-232. doi:10.1188/08.ONF.225232

28. Kaminski M, Pellino T, Wish J. Play and pets: the physical and emotional impact of child-life and pet therapy on hospitalized children. Child Health Care. 2002;31:321-335. doi:10.1207/S15326888CHC3104_5

29. Silva NB, Osório FL. Impact of an animal-assisted therapy programme on physiological and psychosocial variables of paediatric oncology patients. PLoS One. 2018;13:e0194731. doi:10.1371/journal.pone.0194731

30. Coakley AB, Mahoney EK. Creating a therapeutic and healing environment with a pet therapy program. Complement Ther Clin Pract. 2009;15:141-146. doi:10.1016/J.CTCP.2009.05.004

31. Phung A, Joyce C, Ambutas S, et al. Animal-assisted therapy for inpatient adults. Nursing. 2017;47:63-66.

32. Chubak J, Hawkes R, Dudzik C, et al. Pilot study of therapy dog visits for inpatient youth with cancer. J Pediatr Oncol Nurs. 2017;34:331-341. doi:10.1177/1043454217712983
33. Ginex P, Montefusco M, Zecco G, et al. Animal-facilitated therapy program: outcomes from caring canines, a program for patients and staff on an inpatient surgical oncology unit. Clin J Oncol Nurs. 2018;22:193-198. doi:10.1188/18. CJON.193-198

34. Kumasaka T, Masu H, Kataoka M, Numao A. Changes in patient mood through animal-assisted activities in a palliative care unit. Int Med J (1994). 2012;19:373-377.

35. Petranek S, Pencek J, Dey M. The effect of pet therapy and artist interactions on quality of life in brain tumor patients: a cross-section of art and medicine in dialog. Behav Sci (Basel). 2018;8:43. doi:10.3390/bs8050043

36. Haylock PJ, Cantril CA. Healing with horses: fostering recovery from cancer with horses as therapists. Explore (NY). 2006;2:264-268. doi:10.1016/j.explore.2006.03.013

37. Muschel IJ. Pet therapy with terminal cancer patients. Soc Casework. 1984;65:451-458.

38. Toro D, del Pilar Valdes M. Animal-assisted therapy as an approach to psychosocial symptoms in oncopediatric patients. Pediatr Blood Cancer. 2010;55:958.

39. Bouchard F, Landry M, Belles-Isles M, Gagnon J. A magical dream: a pilot project in animal-assisted therapy in pediatric oncology. Can Oncol Nurs J. 2004;14:14-17.

40. Gagnon J, Bouchard F, Landry M, Belles-Isles M, Fortier M, Fillion L. Implementing a hospital-based animal therapy program for children with cancer: a descriptive study. Can Oncol Nurs J. 2004;14:217-222. doi:10.5737/11819 $12 \times 144217222$

41. Marcus DA, Blazek-O’Neill B, Kopar JL. Symptom reduction identified after offering animal-assisted activity at a cancer infusion center. Am J Hosp Palliat Med. 2014;31:420421. doi:10.1177/1049909113492373

42. Moreira RL, do Amaral Gubert F, de Sabino LMM, et al. Assisted therapy with dogs in pediatric oncology: relatives' and nurses' perceptions. Rev Bras Enferm. 2016;69:11881194. doi:10.1590/0034-7167-2016-0243

43. Schmitz A, Beermann M, MacKenzie CR, Fetz K, SchulzQuach C. Animal-assisted therapy at a university centre for palliative medicine - a qualitative content analysis of patient records. BMC Palliat Care. 2017;16:50. doi:10.1186/s12904017-0230-z

44. Bibbo J. Staff members' perceptions of an animalassisted activity. Oncol Nurs Forum. 2013;40:E320-E326. doi:10.1188/13.ONF.E320-E326

45. White JH, Quinn M, Garland S, et al. Animal-assisted therapy and counseling support for women with breast cancer: an exploration of patient's perceptions. Integr Cancer Ther. 2015;14:460-467. doi:10.1177/1534735415580678

46. Caprilli S, Messeri A. Animal-assisted activity at A. Meyer Children's Hospital: a pilot study. Evid Based Complement Alternat Med. 2006;3:379-383. doi:10.1093/ecam/nel029

47. Aiba N, Bando Y, Yamamoto H, et al. Multifaceted effects of animal-assisted therapy in a lethargic patient with colon cancer and comorbidities: a case report. Integr Med Res. 2015;4(1 suppl):24. Accessed July 28, 2018. https://www.imr-journal. com/article/S2213-4220(15)00368-6/abstract

48. Yom SS. The softer (and furrier) side of oncology. Pract Radiat Oncol. 2016;6:285-286. doi:10.1016/j.prro.2016.01.003 
49. Chubak J, Hawkes R. Animal-assisted activities: results from a survey of top-ranked pediatric oncology hospitals. J Pediatr Oncol Nurs. 2016;33:289-296. doi:10.1177/1043454215614961

50. Buettner LL, Wang YC, Stevens K, Jessup H, Magrinat GC. Perceived benefits of animal-assisted therapy in the oncology waiting room. Am J Recreat Ther. 2011;10:25-34. doi:10.5055/ajrt.2011.0008

51. Larson BR, Looker S, Herrera DM, et al. Cancer patients and their companion animals: results from a 309-patient survey on petrelated concerns and anxieties during chemotherapy. $J$ Cancer Educ. 2010;25:396-400. doi:10.1007/s13187-010-0062-5

52. Doobrow B. The Child Life Specialists' Perception of Animal Assisted Therapy Within a Pediatric Oncology Population [master's thesis]. East Carolina University; 2016. Accessed July 28, 2018. http://thescholarship.ecu.edu/handle/10342/5353

53. Nimer J, Lundahl B. Animal-assisted therapy: a meta-analysis. Anthrozoos. 2007;20:225-238. doi:10.2752/0892793 $07 X 224773$

54. Marcus DA. The science behind animal-assisted therapy. Curr Pain Headache Rep. 2013;17:322. doi:10.1007/s11916013-0322-2

55. Katayama M, Kubo T, Mogi K, Ikeda K, Nagasawa M, Kikusui T. Heart rate variability predicts the emotional state in dogs. Behav Processes. 2016;128:108-112. doi:10.1016/j. beproc.2016.04.015

56. Lee DY, Kim E, Choi MH. Technical and clinical aspects of cortisol as a biochemical marker of chronic stress. BMB Rep. 2015;48:209-216. doi:10.5483/BMBREP.2015.48.4.275

57. Dreschel NA, Granger DA. Physiological and behavioral reactivity to stress in thunderstorm-phobic dogs and their caregivers. Appl Anim Behav Sci. 2005;95:153-168. doi:10.1016/J. APPLANIM.2005.04.009

58. Bennett A, Hayssen V. Measuring cortisol in hair and saliva from dogs: coat color and pigment differences. Domest Anim Endocrinol. 2010;39:171-180. doi:10.1016/J. DOMANIEND.2010.04.003

59. Kellner R. A symptom questionnaire. J Clin Psychiatry. 1987;48:268-274.

60. Fava GA, Kellner R. Prodromal symptoms in affective disorders. Am J Psychiatry. 1991;148:823-830. doi:10.1176/ ajp.148.7.823

61. Lundqvist M, Carlsson P, Sjödahl R, Theodorsson E, Levin LÅ. Patient benefit of dog-assisted interventions in health care: a systematic review. BMC Complement Altern Med. 2017; 17:358. doi:10.1186/s12906-017-1844-7

62. Foster M, Beppler E, Holder T, et al. A system for assessment of canine-human interaction during animal-assisted therapies. Conf Proc IEEE Eng Med Biol Soc. 2018;2018:4347-4350. doi:10.1109/EMBC.2018.8513384
63. Di Nardo F, Anfossi L, Ozella L, et al. Validation of a qualitative immunochromatographic test for the noninvasive assessment of stress in dogs. J Chromatogr B Anal Technol Biomed Life Sci. 2016;1028:192-198. doi:10.1016/j. jchromb.2016.06.019

64. Aoki J, Iwahashi K, Ishigooka J, et al. Evaluation of cerebral activity in the prefrontal cortex in mood [affective] disorders during animal-assisted therapy (AAT) by near-infrared spectroscopy (NIRS): a pilot study. Int J Psychiatry Clin Pract. 2012;16:205-213. doi:10.3109/13651501.2011.644565

65. Lee SP, Cheok AD, James TKS, et al. A mobile pet wearable computer and mixed reality system for human-poultry interaction through the internet. Pers Ubiquitous Comput. 2006;10:301-317. doi:10.1007/s00779-005-0051-6

66. Cherniack EP, Cherniack AR. The benefit of pets and animal-assisted therapy to the health of older individuals. Curr Gerontol Geriatr Res. 2014;2014:623203. doi:10.1155/2014/623203

67. Kruger KA, Serpell JA. Animal-assisted interventions in mental health: definitions and theoretical foundations. In: AH Fine, ed. Handbook on Animal-Assisted Therapy: Theoretical Foundations and Guidelines for Practice. 3rd ed. Academic Press; 2010:33-48. doi:10.1016/B978-0-12381453-1.10003-0

68. Gilmer MJ, Baudino MN, Tielsch Goddard A, Vickers DC, Akard TF. Animal-assisted therapy in pediatric palliative care. Nurs Clin North Am. 2016;51:381-395. doi:10.1016/j. cnur.2016.05.007

69. Palley LS, O'Rourke PP, Niemi SM. Mainstreaming animalassisted therapy. ILAR J. 2010;51:199-207.

70. McCullough A, Ruehrdanz A, Jenkins M, Ganzert R. The importance of assessing behavioral and physiological stress in therapy dogs. Austin J Vet Sci Anim Husb. 2015;2:1008.

71. Waite TC, Hamilton L, O'Brien W. A meta-analysis of animal assisted interventions targeting pain, anxiety and distress in medical settings. Complement Ther Clin Pract. 2018;33:4955. doi:10.1016/j.ctcp.2018.07.006

72. Konigorski L, Litorell C. Vårdhund i barnsjukvård: litteraturöversikt. Published 2017. Accessed July 28, 2018. http:// www.diva-portal.org/smash/record.jsf?pid=diva2\%3A10956 96\&dswid=-9778

73. Andreu JAL, Monleón MCB. Adoption of assistance dogs as anxiolytics and positive stimulation during hospitalization. Rev Española Pediatr. 2017;73:219. Accessed March 29, 2019. http://www.ndsl.kr/ndsl/search/detail/article/articleSearchResultDetail.do?cn=NART78959810

74. Borgatti A, Buracco P. A bond beyond friendship: dog, man, and comparative oncology. Veterinaria (Cremona). 2009;23:9-25. Accessed March 29, 2019. https://habricentral. org/resources/21605 